NBER WORKING PAPER SERIES

R\&D INVESTMENT, EXPORTING, AND PRODUCTIVITY DYNAMICS

\author{
Bee Yan Aw \\ Mark J. Roberts \\ Daniel Yi Xu \\ Working Paper 14670 \\ http://www.nber.org/papers/w14670
}

\author{
NATIONAL BUREAU OF ECONOMIC RESEARCH \\ 1050 Massachusetts Avenue \\ Cambridge, MA 02138 \\ January 2009
}

We thank Jan De Loecker, Ulrich Doraszelski, Marc Melitz, Ariel Pakes, Nina Pavnick, and Jim Tybout for helpful discussions and comments. We are grateful to Yi Lee for helping us to acquire and understand the data. All remaining errors are ours. The views expressed herein are those of the author(s) and do not necessarily reflect the views of the National Bureau of Economic Research.

NBER working papers are circulated for discussion and comment purposes. They have not been peerreviewed or been subject to the review by the NBER Board of Directors that accompanies official NBER publications.

(C) 2009 by Bee Yan Aw, Mark J. Roberts, and Daniel Yi Xu. All rights reserved. Short sections of text, not to exceed two paragraphs, may be quoted without explicit permission provided that full credit, including $(\odot$ notice, is given to the source. 
R\&D Investment, Exporting, and Productivity Dynamics

Bee Yan Aw, Mark J. Roberts, and Daniel Yi Xu

NBER Working Paper No. 14670

January 2009, Revised October 2010

JEL No. F14,O31,O33

\begin{abstract}
A positive correlation between productivity and export market participation has been well documented in producer micro data. Recent empirical studies and theoretical analyses have emphasized that this may reflect the producer's other investment activities, particularly investments in R\&D or new technology, that both raise productivity and increase the payoff to exporting. In this paper we develop a dynamic structural model of a producer's decision to invest in R\&D and participate in the export market. The investment decisions depend on the expected future profitability and the fixed and sunk costs incurred with each activity. We estimate the model using plant-level data from the Taiwanese electronics industry and find a complex set of interactions between $R \& D$, exporting, and productivity. The self- selection of high productivity plants is the dominant channel driving participation in the export market and R\&D investment. Both R\&D and exporting have a positive direct effect on the plant's future productivity which reinforces the selection effect. When modeled as discrete decisions, the productivity effect of $\mathrm{R} \& \mathrm{D}$ is larger, but, because of its higher cost, is undertaken by fewer plants than exporting. The impact of each activity on the net returns to the other are quantitatively unimportant. In model simulations, the endogenous choice of $R \& D$ and exporting generates average productivity that is 22.0 percent higher after 10 years than an environment where productivity evolution is not affected by plant investments.
\end{abstract}

Bee Yan Aw

Department of Economics

The Pennsylvania State University

University Park, PA 16802

byr@psu.edu

Mark J. Roberts

Department of Economics

513 Kern Graduate Building

Pennsylvania State University

University Park, PA 16802

and NBER

mroberts@psu.edu
Daniel Yi Xu

Department of Economics

New York University

19 West Fourth Street, Sixth Floor

New York, NY 10012

and NBER

daniel.xu@nyu.edu 


\title{
R\&D Investment, Exporting, and Productivity Dynamics
}

\author{
By Bee Yan Aw, Mark J. Roberts, and Daniel Yi XU*
}

\begin{abstract}
This paper estimates a dynamic structural model of a producer's decision to invest in $R \& D$ and export, allowing both choices to endogenously affect the future path of productivity. Using plant-level data for the Taiwanese electronics industry, both activities are found to have a positive effect on the plant's future productivity. This in turn drives more plants to self-select into both activities, contributing to further productivity gains. Simulations of an expansion of the export market are shown to increase both exporting and $R \& D$ investment and generate a gradual within-plant productivity improvement.

JEL: F14, O31, O33

Keywords: Export, R\&D investment, Productivity Growth, Taiwan Electronics Industry
\end{abstract}

A large empirical literature using firm and plant-level data documents that, on average, exporting producers are more productive than nonexporters. A general finding is that this reflects the self-selection of more productive firms into the export market but, in some cases, may also reflect a direct effect of exporting on future productivity gains. ${ }^{1}$ A further possibility is that there is a spurious component to the correlation reflecting the fact that some firms undertake investments that lead to both higher productivity and a higher propensity to export.

Recently, several authors have begun to measure the potential role of the firms' own investments in R\&D or technology adoption as a potentially important component of the productivityexport link. Andrew B. Bernard and J. Bradford Jensen (1997), Mary Hallward-Driemeier, Giuseppe Iarossi, and Kenneth L. Sokoloff (2002), John R. Baldwin and Wulong Gu (2004), Bee Yan Aw, Mark J. Roberts, and Tor Winston (2007), Paula Bustos (forthcoming), Alla Lileeva and Daniel Trefler (forthcoming), Leonardo Iacovone and Beata S. Javorcik (2007), Bee Yan Aw, Mark J. Roberts, and Daniel Yi Xu (2008) and Jože P. Damijan, Črt Kostevc, and Sašo Polanec (2008) find evidence from micro data sets that exporting is also correlated with firm investment in R\&D or adoption of new technology that can also affect productivity. Complementing this evidence, Chiara Criscuolo, Jonathan Haskel, and Matthew Slaughter (2005) analyze survey data collected for E.U. countries and find that firms that operate globally devote more resources to assimilating knowledge from abroad and generate more innovations and productivity improvement. A key implication of these studies is that the technology and export decisions are interdependent and both channels may endogenously affect the firm's future productivity.

The effects of a trade liberalization that lowers trade costs or expands export markets will depend crucially on the micro-level relationship between productivity, exporting, and R\&D or technology investment. Two recent theoretical papers, Andrew Atkeson and Ariel Burstein (forthcoming) and James A. Constantini and Marc J. Melitz (2008), have formalized how trade liberalizations can increase the rate of return to a firm's R\&D or investment in new technology and thus

* Aw: The Pennsylvania State University, Department of Economics, 501 Kern Building, University Park, PA 16870, (e-mail: byr@psu.edu). Roberts: The Pennsylvania State University, Department of Economics, 513 Kern Building, University Park, PA 16870 and National Bureau of Econmic Research, (e-mail: mroberts@psu.edu). Xu: New York University, Department of Economics, 19 West Fourth Street, Sixth Floor, New York, NY 10012 and National Bureau of Economic Research, (e-mail: daniel.xu@nyu.edu). We thank Jan De Loecker, Ulrich Doraszelski, Jonathan Eaton, José Carlos Fariñas, Oleg Itskhoki, Marc Melitz, Ariel Pakes, Nina Pavnick, Jim Tybout and two anonymous referees for helpful discussions and comments. We are grateful to Yi Lee for helping us to acquire and understand the data. All remaining errors are ours.

${ }^{1}$ See Greenaway and Kneller (2007) for a recent survey of the micro econometric evidence on this topic. 
lead to future endogenous productivity gains. Both papers share several common features. First, productivity is the underlying state variable that distinguishes heterogeneous producers. Second, productivity evolution is endogenous, affected by the firm's innovation decisions, and contains a stochastic component. Third, while they differ in the specific structure of costs and information, they each identify pathways through which export market size affects the firm's choice to export or invest in new technology. Quantifying these pathways is key to understanding the long-run impacts of trade liberalization.

In this paper we develop and estimate a dynamic, structural model of exporting and R\&D investment using data for Taiwanese manufacturing plants in the electronics products industry for the period 2000-2004. We use the model to quantify the linkages between the export decision, R\&D investment, and endogenous productivity growth and then simulate the long-run impacts of an export demand expansion on these variables. This provides a methodology for studying the effects of trade liberalization on productivity growth without data from a natural experiment. As part of our model we estimate the dynamic decision rules for the plant's optimal choice of R\&D and exporting where these rules depend on the expected future profits and the current fixed or sunk costs of each activity. We quantify three pathways linking exporting, R\&D investment, and productivity. First, the return to each investment increases with the producer's underlying productivity which leads high-productivity producers to self-select into both investment activities. Second, each investment directly affects future productivity which acts to reinforce the selection effect. Third, as emphasized in the recent theoretical models, policy changes that alter the future return to one activity, such as a reduction in trade costs or an R\&D subsidy, affect the probability of both activities.

Our empirical results reveal a rich set of productivity determinants. Productivity evolution is endogenous, being impacted positively by both R\&D investment and exporting and, when modeled as discrete activities, the impact of $R \& D$ is larger. There are significant entry costs for both activities, which introduces a second source of intertemporal linkages in the decisions, and the costs of undertaking R\&D activities are larger than the costs of exporting. The selfselection of high productivity plants is the dominant channel driving export market participation and R\&D investment and this is reinforced by the effect of each investment on future productivity. Holding expected export market demand constant, whether or not a firm invested in R\&D in the past has very little direct impact on the net returns to exporting or the probability the firm exports. Similarly, past export experience has very little direct impact on the return to R\&D or the probability of undertaking R\&D.

Using the model we conduct counterfactual exercises to quantify the effect of a permanent reduction in trade costs that increases export demand on plant exporting, $R \& D$, and productivity change. Bustos (forthcoming) and Lileeva and Trefler (forthcoming) have studied periods of trade liberalization in Argentina and Canada and found evidence that reductions in tariffs faced by exporting firms lead to increases in exporting, innovative activities by the firm, or productivity. We find that an expansion in export market size would increase the export and R\&D participation rates by 10.2 and 4.7 percentage points, respectively, after 15 years. This would lead to an increase in mean plant productivity of 5.3 percent. This reflects the cumulative effect of increased exporting and $R \& D$ on productivity and the effect of these productivity gains on the self-selection of plants into these activities. We isolate the individual roles of $\mathrm{R} \& \mathrm{D}$ and exporting by comparing our counterfactual results with those generated by more restrictive productivity processes and find that, in the environment with endogenous plant productivity, the expansion of the export market leads to an increase in mean productivity that is twice as large as the increase that would occur under more restrictive environments. The combination of larger export markets and the plant's ability to invest and endogenously affect its future productivity contributes to larger productivity gains.

The next section of this paper develops the theoretical model of the firm's dynamic decision to invest in R\&D and exporting. The third section develops a two-stage estimation method for the 
model. The first stage estimates the underlying process for producer productivity and the second stage uses this to estimate the dynamic decision rules for R\&D and export market participation. The fourth section provides a brief discussion of the data source. The fifth section summarizes the parameter estimates, measures the costs and marginal returns to R\&D investment and export market participation, and conducts the counterfactual exercise to quantify the productivity effects of an expansion of export demand.

\section{A Structural Model of Exporting and R\&D}

The theoretical model developed in this section is similar in several ways to the models of exporting developed by Mark J. Roberts and James R. Tybout (1997), Sofronis K. Clerides, Saul Lach, and James R. Tybout (1998), Marc J. Melitz (2003), and Sanghamitra Das, Mark J. Roberts, and James R. Tybout (2007) and the models of exporting and investment by Atkeson and Burstein (forthcoming) and Constantini and Melitz (2008). We abstract from the decision to enter or exit production and instead focus on the investment decisions and process of productivity evolution. Firms are recognized to be heterogeneous in their productivity and the export demand curve they face. Together these determine each firm's incentive to invest in R\&D and to export. In turn, these investments have feedback effects that can alter the path of future productivity for the firm. We divide the firm's decision making into a static component, where the firm's productivity determines its short-run profits from exporting, and a dynamic component where they make optimal R\&D and export-market participation decisions.

\section{A. Static Decisions}

We begin with a model of the firm's revenue in the domestic and export markets. Firm $i$ 's short-run marginal cost function is written as:

$$
\ln c_{i t}=\operatorname{lnc}\left(k_{i t}, w_{t}\right)-\omega_{i t}=\beta_{0}+\beta_{k} \ln k_{i t}+\beta_{w} \ln w_{t}-\omega_{i t}
$$

where $k_{i t}$ is firm capital stock, $w_{t}$ is a vector of variable input prices common to all firms, and $\omega_{i t}$ is firm productivity. ${ }^{2}$ Several features of the specification are important. The firm is assumed to produce a single output which can be sold in both domestic and export markets and marginal cost is identical across the two markets for a firm. There are two sources of short-run cost heterogeneity, capital stocks that are observable in the data and firm productivity that is observable to the firm but not observable in our data. Marginal cost does not vary with the firm's output level which implies that demand shocks in one market do not affect the static output decision in the other market and allows us to model revenue and profits in each market independently of the output level in the other market. ${ }^{3}$

Both the domestic and export markets are assumed to be monopolistically competitive and segmented from each other. This rules out strategic interaction among firms in each market but does allow firms to charge markups that differ across markets. The demand curves faced by firm $i$ in the domestic and export markets are assumed to have the Dixit-Stiglitz form. In the domestic market it is:

$$
q_{i t}^{D}=Q_{t}^{D}\left(p_{i t}^{D} / P_{t}^{D}\right)^{\eta_{D}}=\frac{I_{t}^{D}}{P_{t}^{D}}\left(\frac{p_{i t}^{D}}{P_{t}^{D}}\right)^{\eta_{D}}=\Phi_{t}^{D}\left(p_{i t}^{D}\right)^{\eta_{D}}
$$

\footnotetext{
${ }^{2}$ Other firm-level cost shifters can be included in the empirical specification. In this version we will focus on the heterogeneity that arises from differences in size, as measured by capital stocks, and productivity.

${ }^{3}$ The domestic market will play an important role in modeling the dynamic decision to invest in R\&D developed later.
} 
where $Q_{t}^{D}$ and $P_{t}^{D}$ are the industry aggregate output and price index, $I_{t}^{D}$ is total market size, and $\eta_{D}$ is the constant elasticity of demand. The firm's demand depends on the industry aggregates, represented by $\Phi_{t}^{D}$, its price $p_{i t}^{D}$, and the constant demand elasticity.

A similar structure is assumed in the export market except that each firm's demand also depends on a firm-specific demand shifter $z_{i t}$. The demand curve firm $i$ faces in the export market is:

$$
q_{i t}^{X}=\frac{I_{t}^{X}}{P_{t}^{X}}\left(\frac{p_{i t}^{X}}{P_{t}^{X}}\right)^{\eta_{X}} \exp \left(z_{i t}\right)=\Phi_{t}^{X}\left(p_{i t}^{X}\right)^{\eta_{X}} \exp \left(z_{i t}\right)
$$

where $\Phi_{t}^{X}$ represents the aggregate export market size and price, $p_{i t}^{X}$ is the firm's export price, $\eta_{X}$ is a common demand elasticity and $z_{i t}$ is a firm-specific demand shock. By including this last term we incorporate an exogenous source of firm-level variation which will allow a firm's relative demands in the domestic and export markets to vary across firms and over time. The firm is assumed to observe $z_{i t}$ when making its export decision, but it is not observable in our data.

Given its demand and marginal cost curves, firm $i$ chooses the price in each market to maximize the sum of domestic and export profits. The first-order condition for the domestic market price $p_{i t}^{D}$ implies that the log of domestic market revenue $r_{i t}^{D}$ is:

$$
\ln r_{i t}^{D}=\left(\eta_{D}+1\right) \ln \left(\frac{\eta_{D}}{\eta_{D}+1}\right)+\ln \Phi_{t}^{D}+\left(\eta_{D}+1\right)\left(\beta_{0}+\beta_{k} \ln k_{i t}+\beta_{w} \ln w_{t}-\omega_{i t}\right)
$$

Specifically, the firm's revenue depends on the aggregate market conditions and the firm-specific productivity and capital stock. Similarly, if the firm chooses to export, export market revenue is:

$$
\ln r_{i t}^{X}=\left(\eta_{X}+1\right) \ln \left(\frac{\eta_{X}}{\eta_{X}+1}\right)+\ln \Phi_{t}^{X}+\left(\eta_{X}+1\right)\left(\beta_{0}+\beta_{k} \ln k_{i t}+\beta_{w} \ln w_{t}-\omega_{i t}\right)+z_{i t}
$$

depending on the aggregate export market conditions, firm productivity, capital stock, and the export market demand shock. In the context of this model, these two equations show that the firm's domestic revenue will provide information on its marginal cost, in particular the productivity level $\omega_{i t}$. The export market revenue will also provide information on the export demand shocks, but only for firms that are observed to export. In the empirical model developed below we will estimate the revenue functions and can interpret the two sources of unobserved heterogeneity $\omega_{i t}$ and $z_{i t}$ more generally. The first term $\omega_{i t}$ will capture any source of firm-level heterogeneity that affects the firm's revenue in both markets. While we will refer to this as productivity, it could include characteristics of the product, such as its quality, that would affect the demand for the firm's product, as well as its cost, in both markets. The $z_{i t}$ term will capture all sources of revenue heterogeneity, arising from either the cost or demand side, that are unique to the export market. We will refer to $z_{i t}$ as the firm's export market shock.

Given these functional form assumptions for demand and marginal cost, there is a simple link between firm revenue and profit in each market. The firm's profit in the domestic market is:

$$
\pi_{i t}^{D}=-\left(\frac{1}{\eta_{D}}\right) r_{i t}^{D}\left(\Phi_{t}^{D}, k_{i t}, \omega_{i t}\right)
$$

where revenue is given above. Similarly, if the firm chooses to export, the profits they will earn 
are linked to export market revenue as:

$$
\pi_{i t}^{X}=-\left(\frac{1}{\eta_{X}}\right) r_{i t}^{X}\left(\Phi_{t}^{X}, k_{i t}, \omega_{i t}, z_{i t}\right)
$$

These equations allow us to measure firm profits from observable data on revenue in each market. These short-run profits will be important determinants of the firm's decision to export and to invest in R\&D in the dynamic model developed in the next two sections.

\section{B. Transition of the State Variables}

In order to model the firm's dynamic optimization problem for exporting and R\&D we begin with a description of the evolution of the process for firm productivity $\omega_{i t}$ and the other state variables $\ln \Phi_{t}^{D}, \ln \Phi_{t}^{X}, z_{i t}$, and $k_{i t}$. We assume that productivity evolves over time as a Markov process that depends on the firm's investments in R\&D, its participation in the export market, and a random shock:

$$
\begin{aligned}
\omega_{i t}= & g\left(\omega_{i t-1}, d_{i t-1}, e_{i t-1}\right)+\xi_{i t} \\
= & \alpha_{0}+\alpha_{1} \omega_{i t-1}+\alpha_{2}\left(\omega_{i t-1}\right)^{2}+\alpha_{3}\left(\omega_{i t-1}\right)^{3}+\alpha_{4} d_{i t-1}+\alpha_{5} e_{i t-1}+ \\
& \alpha_{6} d_{i t-1} e_{i t-1}+\xi_{i t}
\end{aligned}
$$

$d_{i t-1}$ and $e_{i t-1}$ are, respectively, the firm's R\&D and export market participation in the previous period. The inclusion of $d_{i t-1}$ recognizes that the firm may affect the evolution of its productivity by investing in R\&D. The inclusion of $e_{i t-1}$ allows for the possibility of learning-by-exporting, that participation in the export market is a source of knowledge or expertise that can improve future productivity. The stochastic nature of productivity improvement is captured by $\xi_{i t}$ which is treated as an iid shock with zero mean and variance $\sigma_{\xi}^{2}{ }^{4}$ This stochastic component represents the role that randomness plays in the evolution of a firm's productivity. It is the innovation in the productivity process between $t-1$ and $t$ that is not anticipated by the firm and by construction is not correlated with $\omega_{i t-1}, d_{i t-1}$, and $e_{i t-1}$. This specification also recognizes that the stochastic shocks to productivity in any year $t$ will carry forward into productivity in future years. The second line of the equation gives the assumed functional form for this relationship: a cubic function of lagged productivity and a full set of interactions between lagged exporting and R\&D.

We model the past R\&D and export choice, $d_{i t-1}$, and $e_{i t-1}$, as discrete $0 / 1$ variables which implies that any firm that undertakes $R \& D$ or exporting has the same expected increment to its productivity, as described by the parameters $\alpha_{4}, \alpha_{5}$, and $\alpha_{6}$ (the realizations will differ because of the stochastic component $\xi_{i t}$ ). This is consistent with the evidence reported by Aw, Roberts, and Winston (2007) who estimate a reduced-form model consistent with the structural model we develop here. They find that productivity evolution for Taiwanese electronics producers is affected by the discrete export and R\&D variables. They also find that firm productivity is a significant determinant of the discrete decision to undertake each of these activities, but find little evidence that productivity is correlated with the level of export market sales for firms that choose these investments.

\footnotetext{
${ }^{4}$ This is a generalization of the productivity process used by G. Steven Olley and Ariel Pakes (1996) in their work on productivity evolution in the U.S. telecommunications industry. They modeled productivity as an exogenous Markov process $\omega_{i t}=g\left(\omega_{i t-1}\right)+\xi_{i t}$. Ulrich Doraszelski and Jordi Jaumandreu (2007) have endogenized productivity by allowing it to depend on the firm's choice of R\&D. They model productivity as $\omega_{i t}=g\left(\omega_{i t-1}, d_{i t-1}\right)+\xi_{i t}$ where $d_{i t-1}$ is the firm's past R\&D expenditure. They also show how their specification generalizes the "knowledge capital" model of productivity developed by Zvi Griliches $(1979,1998)$.
} 
The firm's export demand shock will be modeled as a first-order Markov process:

$$
z_{i t}=\rho_{z} z_{i t-1}+\mu_{i t}, \mu_{i t} \sim N\left(0, \sigma_{\mu}^{2}\right) .
$$

If a source of firm-level heterogeneity like $z$ was not included in this model, there would be a perfect cross-section correlation between domestic and export revenue. In our application it is important to allow persistence in the evolution of $z$ because it is going to capture factors like the nature of the firm's product, the set of countries they export to, and any long-term contractual or reputation effects that lead to persistence in the demand for its exports over time. ${ }^{5}$

In modeling the dynamic decisions to export and invest in R\&D, the firm's capital stock, $k_{i}$, will be treated as fixed over time. We recognize the differences in capital stocks across firms but do not attempt to model the firm's investment in capital. Given the relatively short time series in our data, virtually all the variation in capital stocks is across firms and there is nothing to be gained in our empirical application by the additional complication of modeling the firm's capital stock as an endogenous state variable. Finally, the aggregate state variables $\ln \Phi_{t}^{D}$ and $\ln \Phi_{t}^{X}$ are treated as exogenous first-order Markov processes that will be controlled for using time dummies in the empirical model.

\section{Dynamic Decisions $-R \& D$ and Exporting}

In this section we develop the firm's dynamic decision to export and invest in R\&D. A firm entering the export market will incur a nonrecoverable sunk cost and this implies that the firm's past export status is a state variable in the firm's export decision. This is the basis for the dynamic models of export participation developed by Roberts and Tybout (1997) and Das, Roberts, and Tybout (2007). We will also incorporate a sunk startup cost for the firm when it begins investing in $R \& D$ and this will make the firm's past $R \& D$ status a state variable in the investment choices. This is similar to Daniel Yi Xu (2008) who estimates a dynamic model of firm R\&D choice where $R \& D$ expenditures affect the future productivity of the firm. Finally, in our model there is one additional intertemporal linkage: productivity is endogenous meaning the firm's export and R\&D choices can affect its future productivity as shown in equation 8 .

While the static profits, equations 6 and 7, earned by the firm are one important component of its decisions, these will also depend on the combination of markets it participates in and the fixed and sunk costs it must incur. It is necessary to make explicit assumptions about the timing of the firm's decision to export and undertake R\&D. We assume that the firm first observes values of the fixed and sunk costs of exporting, $\gamma_{i t}^{F}$ and $\gamma_{i t}^{S}$, and makes its discrete decision to export in year $t$. Following this, it observes a fixed and sunk cost of investment, $\gamma_{i t}^{I}$ and $\gamma_{i t}^{D}$, and makes the discrete decision to undertake R\&D. ${ }^{6}$ These costs are the expenditures that the firm must make to realize the productivity gains that are given by equation 8 . These expenditures will differ across firms because of differences in technological opportunities and expertise and we assume the firm observes its required expenditure before it makes its discrete decision to undertake R\&D

\footnotetext{
${ }^{5}$ This formulation does not imply that the firm's R\&D cannot affect its profitability in the export market. We just assume that whatever role R\&D plays it works through $\omega$ and affects the firm's revenue and profits in both the domestic and export market. In our data, the R\&D variable measures the firm's investments to develop and introduce new products and to improve its production processes. This variable is best incorporated in our model by allowing it to affect both markets. If separate data were available on R\&D expenditures to develop new products and expenditures to improve production processes then some other specifications could be developed. For example, it would be possible to allow the process R\&D variable to affect both markets through $\omega$ while the new product expenditures acted to shift export demand through $z$.

${ }^{6}$ An alternative assumption is that the firm simultaneously chooses $d$ and $e$. This will lead to a multinomial model of the four possible combinations of exporting and R\&D investment. In the empirical application, it is more difficult to calculate the probability of each outcome in this environment.
} 
or export. Since we do not know the underlying technological opportunities for each firm we model these four expenditures as iid draws from a known joint distribution $G^{\gamma}$. One goal of the empirical model is to estimate parameters that characterize the cost distribution.

The state vector for firm $i$ in year $t$ is $s_{i t}=\left(\omega_{i t}, z_{i t}, k_{i}, \Phi_{t}, e_{i t-1,} d_{i t-1}\right)$ and the firm's value function in year $t$, before it observes its fixed and sunk costs, can be written as:

$$
V_{i t}\left(s_{i t}\right)=\int\left(\pi_{i t}^{D}+\max _{e_{i t}}\left\{\left(\pi_{i t}^{X}-e_{i t-1} \gamma_{i t}^{F}-\left(1-e_{i t-1}\right) \gamma_{i t}^{S}\right)+V_{i t}^{E}\left(s_{i t}\right), V_{i t}^{D}\left(s_{i t}\right)\right\}\right) d G^{\gamma}
$$

where $e_{i t-1}$ is a discrete $0 / 1$ variable identifying the firm's export status in $t-1$. If the firm exported in $t-1$ it pays the fixed $\operatorname{cost} \gamma_{i t}^{F}$ when exporting in period $t$, otherwise it pays the sunk entry $\operatorname{cost} \gamma_{i t}^{S}$ to participate. $V^{E}$ is the value of an exporting firm after it makes its optimal R\&D decision and, similarly, $V_{i t}^{D}$ is the value of a non-exporting firm after it makes its optimal R\&D decision. This equation shows that the firm chooses to export in year $t$ when the current plus expected gain in future export profit exceeds the relevant fixed or sunk cost. In this equation the value of investing in $\mathrm{R} \& \mathrm{D}$ is subsumed in $V_{i t}^{D}$ and $V_{i t}^{E}$. Specifically,

$$
\begin{aligned}
\text { (11) } V_{i t}^{E}\left(s_{i t}\right)= & \int \max _{d_{i t}}\left\{\delta E_{t} V_{i t+1}\left(s_{i t+1} \mid e_{i t}=1, d_{i t}=1\right)-d_{i t-1} \gamma_{i t}^{I}-\left(1-d_{i t-1}\right) \gamma_{i t}^{D},\right. \\
& \left.\delta E_{t} V_{i t+1}\left(s_{i t+1} \mid e_{i t}=1, d_{i t}=0\right)\right\} d G^{\gamma}
\end{aligned}
$$

The first term shows that if the firm chooses to undertake R\&D $\left(d_{i t}=1\right)$ then it pays a current cost that depends on its prior $\mathrm{R} \& \mathrm{D}$ choice. If it invested in $\mathrm{R} \& \mathrm{D}$ in $t-1$ then it pays the fixed investment $\cos t \gamma_{i t}^{I}$ otherwise it pays the sunk startup cost $\gamma_{i t}^{D}$. It has an expected future return which depends on how $\mathrm{R} \& \mathrm{D}$ affects future productivity. If they do not choose to invest $\left(d_{i t}=0\right)$ they have a different future productivity path. The larger the impact of R\&D on future productivity, the larger the difference between the expected returns of doing R\&D versus not doing R\&D and thus the more likely the firm is to invest in R\&D. Similarly, the value of R\&D to a non-exporting firm is:

$$
\begin{aligned}
\text { (12) } V_{i t}^{D}\left(s_{i t}\right)= & \int \max _{d_{i t}}\left\{\delta E_{t} V_{i t+1}\left(s_{i t+1} \mid e_{i t}=0, d_{i t}=1\right)-d_{i t-1} \gamma_{i t}^{I}-\left(1-d_{i t-1}\right) \gamma_{i t}^{D},\right. \\
& \left.\delta E_{t} V_{i t+1}\left(s_{i t+1} \mid e_{i t}=0, d_{i t}=0\right)\right\} d G^{\gamma}
\end{aligned}
$$

where the firm faces the same tradeoff, but now the future productivity paths will be those for a non-exporter. Finally, to be specific, the expected future value conditional on different choices for $e_{i t}$ and $d_{i t}$ is:

$$
E_{t} V_{i t+1}\left(s_{i t+1} \mid e_{i t}, d_{i t}\right)=\int_{\Phi^{\prime}} \int_{z^{\prime}} \int_{\omega^{\prime}} V_{i t+1}\left(s^{\prime}\right) d F\left(\omega^{\prime} \mid \omega_{i t}, e_{i t}, d_{i t}\right) d F\left(z^{\prime} \mid z_{i t}\right) d G\left(\Phi^{\prime} \mid \Phi_{t}\right)
$$

In this equation the evolution of productivity $d F\left(\omega^{\prime} \mid \omega_{i t}, e_{i t}, d_{i t}\right)$ is conditional on both $e_{i t}$ and $d_{i t}$ because of the assumption in equation 8 .

In this framework, the net benefits of both exporting and R\&D investment are increasing in current productivity. This leads to the usual selection effect where high productivity firms are more likely to export and invest in R\&D. By making future productivity endogenous, this model recognizes that current choices lead to improvements in future productivity and thus more firms 
will self-select into, or remain in, exporting and R\&D investment in the future.

When we have two choice variables for the firm, there are new forces in addition to the selection effect which make the decisions interdependent. First, whether or not the firm chooses to export in year $t$ affects the return to investing in R\&D. For any state vector, we can define the marginal benefit of doing R\&D from equations 11 and 12 as the difference in the expected future returns between choosing and not choosing R\&D:

$$
M B R_{i t}\left(s_{i t} \mid e_{i t}\right)=E_{t} V_{i t+1}\left(s_{i t+1} \mid e_{i t}, d_{i t}=1\right)-E_{t} V_{i t+1}\left(s_{i t+1} \mid e_{i t}, d_{i t}=0\right) .
$$

This will depend on the impact of R\&D on future productivity but also on the firm's export choice $e_{i t}$ because of the effect of the sunk cost of exporting and the direct effect of exporting on future productivity through equation 8 . In the special case where the sunk cost of exporting $\gamma_{i t}^{S}=0$ and exporting does not affect the evolution of productivity $\left(\alpha_{5}=\alpha_{6}=0\right.$ in equation 8), exporting becomes a static decision and $M B R_{i t}$ will not be a function of $e_{i t}$ implying that an exporter and a non-exporter will have the same valuation of R\&D investment. ${ }^{7}$

In general, $M B R_{i t}$ will differ for exporters and nonexporters and the sign and magnitude of the difference will depend on the combined effect of the sunk cost of exporting and the sign of the interaction effect between R\&D and exporting on productivity, which is given by the coefficient $\alpha_{6}$ in equation 8. Define the difference in the future benefit of R\&D between exporters and nonexporters as $\triangle M B R_{i t}\left(s_{i t}\right)=M B R_{i t}\left(s_{i t} \mid e_{i t}=1\right)-M B R_{i t}\left(s_{i t} \mid e_{i t}=0\right)$. If $\alpha_{6}>0$ then $\mathrm{R} \& \mathrm{D}$ will be more valuable to exporters and $\triangle M B R>0$. As $\alpha_{6}$ falls, $\triangle M B R$ also declines and can become negative if $\alpha_{6}$ is negative and the sunk cost of exporting is sufficiently small. In this case nonexporters will be more likely to undertake R\&D projects. One way to interpret this is to recognize that $d$ and $e$ are both tools that the firm can employ to acquire knowledge and expertise in order to improve its future productivity. If the two activities are essentially substitutes in the type of knowledge or expertise they bring to the firm, there will be diminishing returns to additional activities and $\alpha_{6}<0$. Conversely, if the knowledge and expertise acquired through the two activities are complementary, for example, a firm that conducts its own R\&D program is better able to assimilate knowledge gained from its export contacts, then there are increasing returns to activities, $\alpha_{6}>0$ and productivity will rise more when the firm adds the second activity. ${ }^{8}$

The expected payoff to exporting will, in general, depend on the firm's past choice of R\&D. From equation 10 exporting provides current export profits $\pi_{i t}^{X}$ and a future benefit that depends on the difference between being in the export market $V_{i t}^{E}$ and remaining only in the domestic market $V_{i t}^{D}$. For any state vector we can define the marginal benefit of exporting as:

$$
M B E_{i t}\left(s_{i t} \mid d_{i t-1}\right)=\pi_{i t}^{X}\left(s_{i t}\right)+V_{i t}^{E}\left(s_{i t} \mid d_{i t-1}\right)-V_{i t}^{D}\left(s_{i t} \mid d_{i t-1}\right)
$$

If there is a sunk cost to initiating an R\&D program, this difference will depend on the firm's previous R\&D choice $d_{i t-1}$. In the special case where there is no sunk cost of R\&D then $V_{i t}^{E}$ and $V_{i t}^{D}$, and thus $M B E_{i t}$, do not depend on $d_{i t-1}$. The incremental impact of R\&D on the return to exporting can be measured by $\triangle M B E_{i t}\left(s_{i t}\right)=M B E_{i t}\left(s_{i t} \mid d_{i t-1}=1\right)-M B E_{i t}\left(s_{i t} \mid d_{i t-1}=0\right)$.

\footnotetext{
${ }^{7}$ This does not imply that the ability to export has no effect on the firm's choice of R\&D. Atkeson and Burstein's (forthcoming) model treats exporting as a static decision but the expectation of lower future fixed costs in the export market increases the firm's incentive to invest in current R\&D. They study the implications of this market size effect on the evolution of industry structure and productivity.

${ }^{8}$ This is the basis for the model of Wesley M. Cohen and Daniel A. Levinthal (1989). In their model R\&D acts to increase the firm's own innovation rate but also to increase its ability to learn or assimilate new information from others.
} 
To summarize the model, firms's differ in their past export market experience, capital stocks, productivity, and export demand and these determine their short-run profits in the domestic and export market. The firm can affect its future productivity and thus profits by investing in R\&D or participating in the export market. These processes, combined with the required fixed or sunk expenditure to export or conduct R\&D, determine the firm's optimal decisions on export market participation and whether or not to undertake $R \& D$. In the next section we detail how we estimate the structural parameters of the profit functions, productivity process, and costs of exporting and conducting R\&D.

\section{Empirical Model and Estimation}

The model of the last section can be estimated using firm or plant-level panel data on export market participation, export market revenue, domestic market revenue, capital stocks, and the discrete R\&D decision. In this section we develop an empirical model which can be estimated in two stages. In the first stage, parameters of the domestic revenue function and the productivity evolution process will be jointly estimated and used to construct the measure of firm productivity. In the second stage, a dynamic discrete choice model of the export and R\&D decision will be developed and used to estimate the fixed and sunk cost of exporting and R\&D and the export revenue parameters. The second-stage estimator is based on the model of exporting developed by Das, Roberts, and Tybout (2007) augmented with the R\&D decision and endogenous productivity evolution. The full set of model parameters includes the market demand elasticities $\eta_{X}$ and $\eta_{D}$, the aggregate demand shifters, $\Phi_{t}^{X}$ and $\Phi_{t}^{D}$, the marginal cost parameters $\beta_{0}, \beta_{k}$, and $\beta_{w}$, the function describing productivity evolution $g\left(\omega_{i t-1}, d_{i t-1}, e_{i t-1}\right)$, the variance of the productivity shocks $\sigma_{\xi}^{2}$, the distribution of the fixed and sunk costs of exporting and R\&D investment $G^{\gamma}$ and the Markov process parameters for the export market shocks, $\rho_{z}$ and $\sigma_{\mu}^{2}$.

\section{A. Demand and Cost Parameters}

We begin by estimating the domestic demand, marginal cost, and productivity evolution parameters. The domestic revenue function in equation 4 is appended with an iid error term $u_{i t}$ that reflects measurement in revenue or optimization errors in price choice:

$$
\ln r_{i t}^{D}=\left(\eta_{D}+1\right) \ln \left(\frac{\eta_{D}}{\eta_{D}+1}\right)+\ln \Phi_{t}^{D}+\left(\eta_{D}+1\right)\left(\beta_{0}+\beta_{k} \ln k_{i t}+\beta_{w} \ln w_{t}-\omega_{i t}\right)+u_{i t}
$$

where the composite error term, $\left(\eta_{D}+1\right)\left(-\omega_{i t}\right)+u_{i t}$ contains firm productivity. We utilize the insights of Olley and Pakes (1996) to rewrite the unobserved productivity in terms of some observable variables that are correlated with it. In general, the firm's choice of the variable input levels for materials, $m_{i t}$, and electricity, $n_{i t}$, will depend on the level of productivity and the export market shock (which are both observable to the firm). Under our assumption that marginal cost is constant in output, the relative expenditures on all the variable inputs will not be a function of total output and thus not depend on the export market shock $z_{i t}$. In addition, if technology differences are not Hick's neutral then differences in productivity will lead to variation across firms and time in the mix of variable inputs used. The material and energy expenditures by the firm will contain information on the productivity level. ${ }^{9}$ Using these insights we can write the level of productivity, conditional on the capital stock, as a function of the variable input levels

\footnotetext{
${ }^{9}$ A large empirical literature has developed models of technical change that are not Hicks neutral. Dale Jorgenson, Frank Gollop, and Barbera Fraumeni (1987) estimate biased technical change using sectoral data. Hans Binswanger (1974) and Rodney Stevenson (1980) are early applications using state and plant-level data, respectively. The empirical studies tend to find that technological change is not Hick's neutral.
} 
$\omega_{i t}\left(k_{i t}, m_{i t}, n_{i t}\right)$. This allows us to use the materials and electricity expenditures by the firm to control for the productivity in equation 16. By combining the demand elasticity terms into an intercept $\gamma_{0}$, and the time-varying aggregate demand shock and market-level factor prices into a set of time dummies $D_{t}$, equation 16 can be written as:

$$
\begin{aligned}
\ln r_{i t}^{D} & =\gamma_{0}+\sum_{t=1}^{T} \gamma_{t} D_{t}+\left(\eta_{D}+1\right)\left(\beta_{k} \ln k_{i t}-\omega_{i t}\right)+u_{i t} \\
& =\gamma_{0}+\sum_{t=1}^{T} \gamma_{t} D_{t}+h\left(k_{i t}, m_{i t}, n_{i t}\right)+v_{i t}
\end{aligned}
$$

where the function $h(\cdot)$ captures the combined effect of capital and productivity on domestic revenue. We specify $h(\cdot)$ as a cubic function of its arguments and estimate equation 17 with ordinary least squares. The fitted value of the $h(\cdot)$ function, which we denote $\hat{\phi}_{i t}$, is an estimate of $\left(\eta_{D}+1\right)\left(\beta_{k} \ln k_{i t}-\omega_{i t}\right) .{ }^{10}$ Next, as in Olley and Pakes (1996) and Doraszelski and Jaumandreu (2007), we construct a productivity series for each firm. This is done by estimating the parameters of the productivity process, equation 8 . Substituting $\omega_{i t}=-\left(\frac{1}{\eta_{D}+1}\right) \hat{\phi}_{i t}+\beta_{k} \ln k_{i t}$ into equation 8 for productivity evolution gives an estimating equation:

$$
\begin{aligned}
\hat{\phi}_{i t}= & \beta_{k}^{*} \ln k_{i t}-\alpha_{0}^{*}+\alpha_{1}\left(\hat{\phi}_{i t-1}-\beta_{k}^{*} \ln k_{i t-1}\right)-\alpha_{2}^{*}\left(\hat{\phi}_{i t-1}-\beta_{k}^{*} \ln k_{i t-1}\right)^{2}+ \\
& \alpha_{3}^{*}\left(\hat{\phi}_{i t-1}-\beta_{k}^{*} \ln k_{i t-1}\right)^{3}-\alpha_{4}^{*} d_{i t-1}-\alpha_{5}^{*} e_{i t-1}-\alpha_{6}^{*} d_{i t-1} e_{i t-1}-\xi_{i t}^{*}
\end{aligned}
$$

where the star represents that the $\alpha$ and $\beta_{k}$ coefficients are multiplied by $\left(\eta_{D}+1\right) .{ }^{11}$ This equation can be estimated with nonlinear least squares and the underlying $\alpha$ and $\beta_{k}$ parameters can be retrieved given an estimate of $\eta_{D}$. Finally, given estimates $\hat{\beta}_{k}$ and $\hat{\eta}_{D}$, we construct an estimate of productivity for each observation as:

$$
\hat{\omega}_{i t}=-\left(1 /\left(\hat{\eta}_{D}+1\right)\right) \hat{\phi}_{i t}+\hat{\beta}_{k} \ln k_{i t}
$$

The final estimating equation in the static demand and cost model exploits the data on total variable cost $(t v c)$. Since each firm's marginal cost is constant with respect to output and equal for both domestic and export output, $t v c$ is the sum of the product of output and marginal cost in each market. Using the first-order condition for profit maximization, marginal cost is equal to marginal revenue in each market and thus $t v c$ is an elasticity-weighted combination of total revenue in each market:

$$
t v c_{i t}=q_{i t}^{D} c_{i t}+q_{i t}^{X} c_{i t}=r_{i t}^{D}\left(1+\frac{1}{\eta_{D}}\right)+r_{i t}^{X}\left(1+\frac{1}{\eta_{X}}\right)+\varepsilon_{i t}
$$

\footnotetext{
${ }^{10}$ In this stage of the estimation we recognize that the firm's capital stock changes over time and incorporate that into the variation in $\hat{\phi}_{i t}$. In the estimation of the dynamic export and R\&D decisions in section 4.2 we simplify the process and keep the firm's capital stock fixed at its mean value over time.

${ }^{11}$ The only exceptions are that $\alpha_{2}^{*}=\alpha_{2}\left(1+\eta_{D}\right)^{-1}$ and $\alpha_{3}^{*}=\alpha_{3}\left(1+\eta_{D}\right)^{-2}$
} 
where the error term $\varepsilon$ is included to reflect measurement error in total cost. This equation provides estimates of the two demand elasticity parameters.

Three key aspects of this static empirical model are worth noting. First, we utilize data on the firm's domestic revenue to estimate firm productivity, an important source of firm heterogeneity that is relevant in both the domestic and export markets. In effect, we use domestic revenue data to estimate and control for one source of the underlying profit heterogeneity in the export market. Second, like Das, Roberts, and Tybout (2007) we utilize data on the firm's total variable cost to estimate demand elasticities and markups in both markets. Third, the method we use to estimate the parameters of the productivity process, equation 8 , can be extended to include other endogenous variables that impact productivity. Estimation of the process for productivity evolution is important for estimating the firm's dynamic investment equations because the parameters from equation 8 are used directly to construct the value functions that underlie the firm's R\&D and export choice, equations 11,12 , and 13 .

\section{B. Dynamic Parameters}

The remaining parameters of the model, the fixed and sunk costs of exporting and investment and the process for the export revenue shocks, can be estimated using the discrete decisions for export market participation, R\&D, and export revenue for the firm's that choose to export. Intuitively, entry and exit from the export market provide information on the distribution of the sunk entry costs $\gamma_{i t}^{S}$ and fixed cost $\gamma_{i t}^{F}$, respectively. The level of export revenue provides information on the distribution of the demand shocks $z_{i t}$ conditional on exporting, which can be used to infer the unconditional distribution for the export shocks. The distribution of the fixed and sunk cost of R\&D investment, $\gamma_{i t}^{I}$ and $\gamma_{i t}^{D}$, are estimated from the discrete R\&D choice.

The dynamic estimation is based on the likelihood function for the observed patterns of firm $i$ exporting $e_{i} \equiv\left(e_{i 0}, \ldots e_{i T}\right)$, export revenue $r_{i}^{X} \equiv\left(r_{i 0}^{X}, \ldots r_{i T}^{X}\right)$, and the discrete patterns of firm R\&D investment $d_{i} \equiv\left(d_{i 0}, \ldots d_{i T}\right)$. Once we recover the first-stage parameter estimates and construct the firm-level productivity series $\omega_{i} \equiv\left(\omega_{i 0}, \ldots \omega_{i T}\right)$, we can write the $i$ th firm's contribution to the likelihood function as:

$$
P\left(e_{i}, d_{i}, r_{i}^{X} \mid \omega_{i}, k_{i}, \Phi\right)=P\left(e_{i}, d_{i} \mid \omega_{i}, k_{i}, \Phi, z_{i}^{+}\right) h\left(z_{i}^{+}\right)
$$

This equation expresses the joint probability of the data as the product of the joint probability of the discrete $e$ and $d$ decisions, conditional on the export market shocks $z$, and the marginal distribution of $z .^{12}$ The variable $z_{i}^{+}$denotes the time series of export market shocks in the years $(0,1, \ldots T)$ when firm $i$ exports. Das, Roberts and Tybout (2007) show how to construct the density $h\left(z_{i}^{+}\right)$given our assumptions on the process for the export market shocks in equation 9. Given knowledge of $h\left(z_{i}^{+}\right)$the export market shocks can be simulated and used in the evaluation of the likelihood function. ${ }^{13}$

A key part of the likelihood function is the joint probability of $\left(e_{i}, d_{i}\right)$. By assuming that the sunk and fixed costs for each firm and year are iid draws from a known distribution, the joint probability of $\left(e_{i}, d_{i}\right)$ can be written as the product of the choice probabilities for $e_{i t}$ and $d_{i t}$ in each year. These choice probabilities in year $t$ are conditioned on the state variables in that year: $\omega_{i t}, z_{i t}, k_{i}, \Phi_{t}, e_{i t-1}$, and $d_{i t-1}$. The lagged export and R\&D choice are part of the

\footnotetext{
${ }^{12}$ In this equation we treat the intercepts of the domestic and export revenue equations as a constant, $\Phi$. We have estimated the model with time-varying intercepts but they were not statistically different from each other in our short panel and we have simplified the estimation by treating them as constant.

${ }^{13}$ Given the assumptions in equation 9, the distribution $h\left(z_{i}^{+}\right)$is normal with a zero mean and a covariance matrix that depends on $\rho_{z}$ and $\sigma_{\mu}^{2}$. If the export market shocks were not serially correlated, equation 21 would take the form of a tobit model. Das, Roberts, and Tybout (2007, section 3) show how to extend the model to the case where $z$ is serially correlated and we use their methodology to allow the export market shocks to be serially correlated.
} 
state vector because they determine whether the firm pays the sunk cost to enter or the fixed cost to remain in year $t$. The model developed above allows us to express the conditional choice probabilities in terms of these costs and the value functions that summarize the payoffs to each activity. Specifically, equation 10 shows the firm's decision to export involves a comparison of the expected profit from exporting relative to remaining in the domestic market with the fixed cost, for previous period exporters, and the sunk cost for nonexporters. From this equation, the probability of exporting can be written as:

$$
P\left(e_{i t}=1 \mid s_{i t}\right)=P\left(e_{i t-1} \gamma_{i t}^{F}+\left(1-e_{i t-1}\right) \gamma_{i t}^{S} \leq \pi_{i t}^{X}+V_{i t}^{E}-V_{i t}^{D}\right)
$$

Similarly, equations 11 and 12 show that the firm compares the increase in expected future value if it chooses to do $R \& D$ with the current period cost of R\&D. The firm's conditional probability of investing in $\mathrm{R} \& \mathrm{D}$ is equal to:

$$
\begin{aligned}
P\left(d_{i t}=1 \mid s_{i t}\right)=\quad & P\left(d_{i t-1} \gamma_{i t}^{I}+\left(1-d_{i t-1}\right) \gamma_{i t}^{D} \leq\right. \\
& \left.\delta E_{t} V_{i t+1}\left(s_{i t+1} \mid e_{i t}, d_{i t}=1\right)-\delta E_{t} V_{i t+1}\left(s_{i t+1} \mid e_{i t}, d_{i t}=0\right)\right)
\end{aligned}
$$

Notice that there is one slight difference in the state vector for the R\&D decision. The current period exports, rather than the lagged exports, are the relevant state variable because of the timing assumption made in the theoretical model. There it was assumed that the firm makes its export and R\&D decisions sequentially, so that current period export status is known prior to choosing R\&D. ${ }^{14}$

The probabilities of investing in R\&D and exporting in equations 22 and 23 depend on the value functions $E_{t} V_{i t+1}, V_{i t}^{E}$, and $V_{i t}^{D}$. For a given set of parameters, these can be constructed by iterating on the equation system defined by $10,11,12$, and 13 . We will evaluate the likelihood function for each set of parameters and rather than attempt to maximize the likelihood function we will utilize a Bayesian Monte Carlo Markov Chain (MCMC) estimator. This changes the objective of estimation to characterizing the posterior distribution of the dynamic parameters. The details of the value-function solution algorithm and the MCMC implementation are contained in the appendix to this paper published on the $A E R$ website. The final detail needed for estimation is a distributional assumption on the fixed and sunk costs. We assume that each of the four costs are drawn from separate independent exponential distributions. The fixed and sunk cost parameters that we estimate are the means of these distributions. With this method it is also simple to allow the cost distributions to vary with some observable characteristic of the firm. For example, we allow the fixed and sunk cost distributions to be different for large and small firms (based on their observed capital stock) and estimate separate exponential distributions for each group.

\section{Data}

\section{A. Taiwanese Electronics Industry}

The model developed in the last section will be used to analyze the sources of productivity change of manufacturing plants in the Taiwanese electronics industry. The micro data used in estimation was collected by the Ministry of Economic Affairs (MOEA) in Taiwan for the years

\footnotetext{
${ }^{14}$ The choice probabilities in equations 22 and 23 are accurate for time periods $1,2 \ldots T$ in the data. In the first year of the data, period 0 , we do not observe the prior period choices for $d$ and $e$ and this leads to an initial conditions problem in estimating the probabilities of exporting or investing in R\&D. We deal with this using James J. Heckman's (1981) suggestion and model the decision to export and conduct $\mathrm{R} \& \mathrm{D}$ in year 0 with separate probit equations. The explanatory variables in year 0 are the state variables $\omega_{i 0}, k_{i}$, and $z_{i 0}$.
} 
2000, and 2002-2004. ${ }^{15}$ There are four broad product classes included in the electronics industry: consumer electronics, telecommunications equipment, computers and storage equipment, and electronics parts and components. The electronics industry has been one of the most dynamic industries in the Taiwanese manufacturing sector. Chia-Hung Sun (2005) reports that over the two decades 1981-1999, the electronics industry averaged total factor productivity growth of 2.0 percent per year, while the total manufacturing sector averaged 0.2 percent. It is also a major export industry. For example, in 2000, the electronics subsector accounted for approximately 40 percent of total manufacturing sector exports. Several authors have discussed the nature of information diffusion from developed country buyers to export producers. ${ }^{16}$ In addition, electronics has also been viewed as Taiwan's most promising and prominent high-tech industry. As reported by National Science Council of Taiwan, $R \& D$ expenditure in the electronics industry accounted for more than 72 percent of the manufacturing total in 2000. Overall, it is an excellent industry in which to examine the linkages between exporting, R\&D investment, and productivity.

The data set that we use is a balanced panel of 1237 plants that were in operation in all four sample years and that reported the necessary data on domestic and export sales, capital stocks, and $\mathrm{R} \& \mathrm{D}$ expenditure. While the survey is conducted at the plant level, the distinction between plant and firm is not important in this sample. Of the sample plants, 1126, 91 percent of the total, are owned by firms that had only a single plant in the electronics industry. The remaining 111 plants are owned by firms that had at least one other plant in the industry in at least one year. Only one plant was owned by a firm that had more than two plants under ownership. This closely mirrors the ownership pattern in the industry as a whole, where, over the period 2000-2004, 92.8 percent of the manufacturing plants were owned by single-plant firms. In the discussion of the empirical results that follows we will use the word plant to refer to the observations in our sample.

Table 1 provides summary measures of the size of the plants, measured as sales revenue. The top panel of the table provides the median plant size across the 1237 plants in our sample in each year, while the bottom panel summarizes the average plant size. The first column summarizes the approximately 60 percent of the plants that do not export in a given year. The median plant's domestic sales varies from 17.0 to 22.2 million new Taiwan dollars. ${ }^{17}$ Among the exporting plants, the median plant's domestic market sales is approximately twice as large, 36.4 to 52.8 million NT dollars. The export sales of the median plant are approximately 32 million NT dollars. It is not the case, however, that there is a perfect correlation between domestic market size and export market size across plants. The simple correlation between domestic and export market revenue is .48 across all plant-year observations and .49 for observations with positive export sales. This suggests that it will be necessary to allow at least two factors to explain the plant-level heterogeneity in revenues in the two markets. The empirical model developed above does this with productivity $\omega_{i t}$ and the export market shock $z_{i t}$.

Table 1 here

The distribution of plant revenue is highly skewed, particularly for plants that participate in the export market. The average domestic plant sales are larger than the medians by a factor of approximately ten for the exporting plants and the average export sales are larger by a factor of approximately 17 . The skewness in the revenue distributions can also be seen from the fact that

\footnotetext{
${ }^{15}$ The survey was not conducted in 2001. In that year a manufacturing sector census was conducted by the Directorate General of Budget, Accounting, and Statistics. This cannot be merged at the plant level with the MOEA survey data for the other years. We use the dynamic model developed in the last section to characterize the plant's productivity, R\&D and export choice for the years 2002-2004 and utilize the information from 2000 to control for the initial conditions problem in the estimation.

${ }^{16}$ The initial arguments for learning-by-exporting, made by Howard Pack (1992), Brian Levy (1994), Michael Hobday (1995), and Larry E. Westphal (2002), were based on case-study evidence for East Asian countries including Taiwan.

${ }^{17}$ In the period 2002-2004, the exchange rate between Taiwan and U.S. dollars was approximately 34 NT\$/US\$. The median plant size is approximately .5 million U.S. dollars
} 
the 100 largest plants in our sample in each year account for approximately 75 percent of the total domestic sales and 91 percent of the export sales in the sample. The skewness in revenues will lead to large differences in profits across plants and a heavy tail in the profit distribution. To fit the participation patterns of all the plants it is necessary to allow the possibility that a plant has large fixed and/or sunk costs. We allow for this in our empirical model by, first, assuming exponential distributions for the fixed and sunk costs and, second, allowing large and small plants to draw their costs from exponential distributions with different means. Together these assumptions allow for substantial heterogeneity in the costs across plants.

The other important variable in the data set is the discrete indicator of R\&D investment. In the survey, R\&D expenditure is reported as the sum of the salaries of R\&D personnel (researchers and scientists), material purchases for R\&D, and R\&D capital (equipment and buildings) expenses. We convert this into a discrete $0 / 1$ variable if the expenditure is positive. ${ }^{18}$ Overall, 18.2 percent of the plant-year observations have positive $R \& D$ expenditures and, for this group, the median expenditure is 11.2 million NT dollars and the mean expenditure is 60.9 million NT dollars. When expressed as a share of total plant sales, the median plant value is .031 and the mean is .064. The R\&D expenditure corresponds to the realization of the fixed cost of $R \& D$ in our model and, as with the export costs, we allow for substantial cost heterogeneity by both assuming exponential distributions for the fixed costs and allowing them to differ for large and small plants.

\section{B. Empirical Transition Patterns for $R \& D$ and Exporting}

The empirical model developed in the last section explains a producer's investment decisions. In this section we summarize the patterns of R\&D and exporting behavior in the sample, with a focus on the transition patterns that are important to estimating the fixed and sunk costs of R\&D and exporting. Table 2 reports the proportion of plants that undertake each combination of the activities and the transition rates between pairs of activities over time. The first row reports the cross-sectional distribution of exporting and $R \& D$ averaged over all years. It shows that in each year, the proportion of plants undertaking neither of these activities is .563. The proportion that conduct R\&D but do not export is .036, export only is .255, and do both activities is .146. Overall, 731 of the sample plants (60 percent) engage in at least one of the investments in at least one year. One straightforward explanation for the difference in export and R\&D participation is that differences in productivity and the export demand shocks affect the return of each activity and the plant's with favorable values of these underlying profit determinants self-select into each activity.

\section{Table 2 here}

The transition patterns among R\&D and exporting are important for the model estimation. The last four rows of the table report the transition rate from each activity in year $t$ to each activity in

\footnotetext{
${ }^{18}$ Another possible source of knowledge acquisition is the purchase of technology from abroad. The survey form asks each plant if it made any purchases of technology. This is a much less common occurence than investing in R\&D. In our data, 18.2 percent of the plant-year observations report positive R\&D expenditures but only 4.9 percent report purchasing technology from abroad. More importantly for estimation of our model, only 31 observations ( 0.62 percent of the sample) report purchasing technology but not conducting their own R\&D. It is not going to be possible to estimate separate effects of R\&D and technology purchases on productivity with this sample. Given our discrete model of R\&D investment, there would be virtually no difference in the data if we defined the discrete variable as investing in R\&D or purchasing technology. We have not used the technology purchase variable in our estimation. Lee Branstetter and Jong-Rong Chen (2006) use this survey data for an earlier, longer time period, 1986-1995, and a more broadly defined industry, electrical machinery and electronics products, and include both technology purchases and R\&D expenditures, measured as continuous variables, in a production function model. They find that both variables are significant in the production function when estimated with random effects and the R\&D elasticity is larger. Neither variable is significant in fixed effects estimates of the production function and they suspect that the reason is measurement error in the variables.
} 
$t+1$. Several patterns are clear. First, there is significant persistence in the status over time. Of the plants that did neither activity in year $t, .871$ of them are in the same category in year $t+1$. Similarly, the probability of remaining in the same category over adjacent years is $.336, .708$, and .767 for the other three categories. This can reflect a combination of high sunk costs of entering a new activity and a high degree of persistence in the underlying sources of profit heterogeneity, which, in our model, are capital stocks $k$, productivity $\omega$, and the export market shocks $z$.

Second, plants that undertake one of the activities in year $t$ are more likely to start the other activity than a plant that does neither. If the plant does neither activity in year $t$, it has a probability of .115 that it will enter the export market. This is lower than the .291 probability that a plant conducting R\&D only will then enter the export market. Similarly, a plant that does neither activity has a .019 probability that it will start investing in $R \& D$, but an exporting plant has a .080 probability of adding R\&D investment as a second activity. Third, plants that conduct both activities in year $t$ are less likely to abandon one of the activities than plants than only conduct one of them. Plants that both export and conduct R\&D have a .171 probability of abandoning R\&D and a .086 probability of leaving the export market. Plants that only do R\&D have a .430 probability of stopping while plants that only export have a .223 probability of stopping.

The transition patterns reported in Table 1 illustrate the need to model the R\&D and exporting decision jointly. In our model, there are three mechanisms linking these activities. One is that plants that do one of the activities may have more favorable values of $k, \omega$, or $z$ that lead them to self-select into the other. A second pathway is that an investment in either activity can affect the future path of productivity as shown in equation 8 and thus the return to both R\&D and exporting. A third pathway is possible for exporting. Even if exporting does not directly enter the productivity evolution process, the return to $\mathrm{R} \& \mathrm{D}$ can be higher or lower for exporting versus nonexporting plants, which makes the probability that the plant will conduct R\&D dependent on the plant's export status.

\section{Empirical Results}

\section{A. Demand, Cost, and Productivity Evolution}

The parameter estimates from the first-stage estimation of equations 18 and 20 are reported in Table 3. The coefficients on the $\omega, d$, and $e$ variables are the $\alpha$ coefficients in equation 8 . We report estimates in column 1 using the discrete measure of R\&D, which we also use in the dynamic model.

Table 3 here

Focusing on the first column, the demand elasticity parameters are virtually identical in the domestic and export markets. The implied value of $\eta_{D}$ is -6.38 and the value of $\eta_{X}$ is -6.10 . These elasticity estimates imply markups of price over marginal cost of 18.6 percent for domestic market sales and 19.6 percent for foreign sales. The coefficient on $\ln k_{i t-1}$ is an estimate of the elasticity of capital in the marginal cost function $\beta_{k}$. It equals -0.063 (s.e.=.0052), implying, as expected, total variable costs are lower for plants with higher capital stock. More interesting are the coefficients for productivity evolution. The coefficients $\alpha_{1}, \alpha_{2}$, and $\alpha_{3}$ measure the effect of the three powers of $\omega_{i t-1}$ on $\omega_{i t}$. They imply a clear significant non-linear relationship between current and lagged productivity. The coefficient $\alpha_{4}$ measures the effect of the lagged discrete R\&D investment on current productivity and it is positive and significant. Plants that are engaged in $R \& D$ investment have 4.79 percent higher productivity. The direct effect of past exporting on current productivity is given by $\alpha_{5}$ and is also positive and significant. This is a measure of the productivity impact of learning-by-exporting and implies the past exporters have productivity that is 1.96 percent higher. The magnitude of the export coefficient is less than half of the magnitude of the R\&D coefficient implying a larger direct productivity impact from R\&D than exporting. 
The last coefficient $\alpha_{6}$ measures an interaction effect from the combination of past exporting and R\&D on productivity evolution. Plants that do both R\&D and exporting have productivity that is 5.56 percent higher than plants that do neither activity. ${ }^{19}$ Plants that do both activities have the highest intercept in the productivity process, but the negative sign on the interaction term implies that the marginal contribution to future productivity of adding the second activity is less than the marginal contribution of adding that same activity when the plant makes no investment. ${ }^{20}$

The coefficients $\alpha_{4}, \alpha_{5}$, and $\alpha_{6}$ imply that the mean long-run productivity level for a plant will depend on the combinations of $e$ and $d$. Relative to a plant that never exports or invests in R\&D $(e=0, d=0)$, a plant that does both in each year $(e=d=1)$ will have mean productivity that is 123 percent higher. ${ }^{21}$ A plant that only conducts $\operatorname{R} \& \mathrm{D}(d=1, e=0)$ in every year will be twice as productive. The smallest improvement is for the firms that only export $(e=1, d=0)$. They will be 34 percent more productive than the base group While this provides a summary of the technology linkages between exporting, $R \& D$, and productivity, it does not recognize the impact of this process on the plant's choice to enter exporting or conduct R\&D. This behavioral response is the focus of the second stage estimation. Given the estimates in Table 3 we construct an estimate of plant productivity from equation 19 . The mean of the productivity estimates is .446 and the $(.05, .95)$ percentiles of the distribution are $(.092, .831)$. This variation in productivity will be one important dimension of heterogeneity in the returns to R\&D and exporting and be important in explaining which plants self-select into these activities. ${ }^{22}$

\section{Table 4 here}

We can assess how well the productivity measure correlates with the plant's R\&D and export choices. In the top panel of Table 4 we report estimates of a bivariate probit regression of exporting and R\&D on the firm's productivity, log capital stock, lagged export dummy, lagged $\mathrm{R} \& \mathrm{D}$ dummy, and a set of time dummies. This regression is similar to the reduced form policy functions that come from our dynamic model. The only difference is the fact that the export demand shocks $z$ are not included explictly but rather captured in the error terms. The bivariate probit model allows the error terms of the two probits to be correlated, as they would be if $z$ was a common omitted factor. In both probit models, all the variables, particularly the productivity

\footnotetext{
${ }^{19} \mathrm{Aw}$, Roberts, and Winston (2007) also studied this industry using data from a 10-year time period, 1986-1996, analyzed at 5-year intervals, and found a similar pattern (Table 6,p. 100). Compared with firms that did neither activity, firms that only exported had productivity that was 4.2 percent higher, firms that only did R\&D had productivity that was 4.7 percent higher, and firms that did both had 7.8 percent higher productivity.

${ }^{20}$ Column 2 of Table 2 repeats the estimation using the $\log$ of $R \& D$ expenditure rather than the discrete variable. This change has no effect on any of the model coefficients except the two coefficients on R\&D, $\alpha_{4}$ and $\alpha_{6}$. The statistical signifiance of $\alpha_{4}$ and the insignificance of $\alpha_{6}$ is not affected. Among the plants that conducted R\&D the mean value of the $\log$ of $R \& D$ expenditure is 9.14. At this mean expenditure, plants that conducted $R \& D$ have productivity that is 6.1 percent higher $(.0610=.00667 * 9.14)$ than plants that make no investment and this is similar to the magnitude of the $R \& D$ effect reported in column 1. In either specification the conclusion about the important role of $R \& D$ is the same. We will utilize the discrete specification in the dynamic model. Although we have a short panel, we experimented with including a second lag of R\&D and exporting in equation 8 . The coefficients on the two-period lags were very small and not statistically significant $(.0093(\mathrm{t}=1.2)$ for $\mathrm{R} \& \mathrm{D}$ and $.0097(\mathrm{t}=1.6)$ for exporting) and so we limit our analysis to a model with one year lags of R\&D and exporting in the productivity evolution equation.

${ }^{21}$ Because the interaction term $\alpha_{6}$ is not statistically significant in Table 3 , we examined the sensitivity of the results if we set the parameter equal to zero. In this case productivity for a plant that always does both activities $(d=e=1)$ will increase more rapidly. The long-run productivity for this plant will be 162 percent higher than for a plant that does neither activity.

${ }^{22}$ These estimates are based on a balanced panel of plants. They are robust if we extend the sample to include all plants that enter or exit during the period. Following the framework in Olley and Pakes (1996) we estimate a probit model for plant exit and include a predicted probability of exit in equation 18. In the probit regression, capital, and the productivity proxies (material and energy use), explain very little of the exit variation. Adding this correction term to equation 18 has virtually no effect on the estimated coefficients reported in Table 3. Finally, there is virtually no difference in the export and $R \& D$ propensities between exiting and surviving plants in the sample. Overall, selection into the domestic market is not an important feature of our data set.
} 
variable, are highly significant. The correlation in the errors is also positive and statistically significant implying that the decisions are driven by some other common factors, such as the export demand shocks $z$. In the second and third panels of Table 4 we report regressions of export revenue, equation 5, for plants that are in the export market. The explanatory variables are productivity, the capital stock, and time dummies. (The lagged export and R\&D dummies do not affect the volume decision once the firm is in the export market). The middle panel reports OLS estimates of the revenue function and the bottom panel treats the export demand shocks as time-invariant plant effects. In both cases the productivity variable is positive and highly significant. ${ }^{23}$ It is important to recognize that this productivity measure has been estimated from the domestic market revenue data. From the fixed effect regression the variation in the plant-specific export demand shocks account for 72 percent of the error variance, suggesting that, even after controlling for productivity, export demand heterogeneity will be an important source of size and profit differences in the export market. Overall, it is clear from these reduced form regressions that the productivity variable we have constructed is measuring an important plant characteristic that is correlated with the discrete export and R\&D decisions and the plant's export revenue once they choose to participate in the market. ${ }^{24}$ In the next section we report the estimates of the dynamic investment equations.

\section{B. Dynamic Estimates}

The remaining cost and export demand parameters are estimated in the second stage of our empirical model using the likelihood function that is the product over the plant-specific joint probability of the data given in equation 21. Each of the four values $\gamma^{I}, \gamma^{D}, \gamma^{F}$ and $\gamma^{S}$ is the parameter of an exponential distribution for, respectively, the R\&D fixed cost, R\&D sunk cost, fixed cost of exporting, and the sunk cost of exporting. The coefficients reported in Table 5 are the means and standard deviations of the posterior distribution of the parameters. The first set of estimates, labeled Model 1, assumes that all plants face the same distributions for the four costs. While we will delay precise statements about the magnitudes of realized sunk and fixed costs until later, two broad patterns are immediately clear from the parameter estimates. First, for each activity, the estimated fixed cost parameter is less than the sunk cost parameter, indicating that the startup costs of each activity are more substantial than the per-period costs of maintaining the activity. Second, the fixed and sunk costs parameters for R\&D are larger than for exporting, indicating that it will be more costly to begin or maintain an R\&D investment program than an export program. ${ }^{25}$

\section{Table 5 here}

In the right side of table 5, labeled Model 2, we divide the plants into two groups based on the size of the capital stock and allow the cost distributions to differ for small (size 1) and large (size 2) plants. The two patterns observed in Model 1 are still present and, in addition, there are differences in the cost distributions faced by large and small plants. The parameter values differ

\footnotetext{
${ }^{23}$ The coefficients on productivity will be subject to a selection bias if the export demand shocks $z$ are correlated with firm productivity $x$. Our estimation of the full structural model recognizes the endogeneity of the decision to export and the fact that the observed realizations of $z$ are drawn from a truncated distribution.

${ }^{24}$ Similar results are reported in Aw, Roberts, and Winston (2007). They estimate a bivariate probit investment model and find that productivity is significant in both investments. They also find that the lagged exporting status is also an important determinant of current investment, which is consistent with the presence of sunk costs of exporting.

${ }^{25}$ To check if our estimates are sensitive to the assumption that plants choose their export status before their R\&D status, we reestimated the model with the alternative pattern for plant decisions. The results in Table 5 change very little as a result and none of our conclusions are affected by this change. It is not surprising that this change has little effect since it only changes the order of integration in equations (10)-(12) but has no effect on equation (13) which is the key component of the future value.
} 
the most for the two fixed cost categories. The smaller parameter value for size 1 plants implies that the scale of operations, either exporting or investing in R\&D, will tend to be smaller for the plants with smaller capital stocks. The final group of parameters describe the stochastic process driving the export market shocks $z$. This is characterized by a first-order autoregressive process with serial correlation parameter equal to 0.763 and a standard deviation for the transitory shocks equal to $\exp (-0.289)=0.75$. This positive serial correlation parameter implies persistence in the plant's export status and export revenue if they choose to be in the market. The parameters estimates for the $z$ process are very similar for Models 1 and 2.

\section{In-Sample Model Performance}

To assess the overall fit of the model, we use the estimated parameters from Model 2 to simulate patterns of $R \& D$ and exporting choice, transition patterns between the choices, and productivity trajectories for the plants in the sample and compare the simulated patterns with the actual data. Since each plant's productivity $\omega_{i t}$ evolves endogenously according to equation 8 , we need to simulate each plant's trajectory of productivity jointly with its dynamic decisions. ${ }^{26}$ In Table 6 we report the actual and predicted percentage of R\&D performers, export market participation rate, and industry mean productivity. Overall, the simulations do a good job of replicating these average data pattern for all three variables.

Table 6 here

Second, we summarize the transition patterns of each plant's export and R\&D status in table 7. The simulated panel performs reasonably well on the transition patterns for all four groups of plants. In particular for the two groups that account of 81.8 percent of the sample observations, those who engage in neither activity and those who only export, the predicted transition patterns match the data very closely. The most difficult transition patterns to fit closely are the ones related to starting or stopping R\&D. Among the group of plants that only conduct R\&D in year $t$, the model tends to overpredict the proportion of plants that will stop R\&D and underestimate the proportion that will continue in year $t+1$. This group of plants accounts for only 3.6 percent of the total observations, however. The model simulations also capture the inter-dependence of the two activities. Plants that undertake one of the activities in year $t$ are more likely to start the other than a plant that does neither. If a plant does neither activity in year $t$, it has a probability of .110 of entering the export market, lower than the .193 probability that a plant conducting R\&D only will also enter the export market. Similarly, a plant that does neither activity has a .019 probability of starting R\&D only, but an exporting plant has a .077 probability of adding R\&D investment. These four transition rates are all similar to what is observed in the data.

Table 7 here

\section{The Determinants of R\&D and Exporting: Productivity, Costs, and History}

In our model the determinants of a plant's export and R\&D choice are its current productivity, prior export and R\&D status, export market shock, capital stock, and cost draws. In this section we will isolate the role of current productivity, the plant's export and R\&D history, and the cost shocks on current R\&D and export choices. Isolating the role of current productivity

\footnotetext{
${ }^{26}$ To do this we take the initial year status $\left(\omega_{i 0}, z_{i 0}, e_{i 0}, k_{i}\right)$ of all plants in our data as given and simulate their next three sample year's export demand shocks $z_{i t}$, R\&D costs $\gamma_{i t}^{I}, \gamma_{i t}^{D}$, and export costs $\gamma_{i t}^{F}, \gamma_{i t}^{S}$. We then use equations $10,11,12$, and 13 to solve each plant's optimal R\&D and export decisions year-by-year. Note that these simulations do not use any data information on a plant's characteristics after their first year. We calculate each plant's domestic and export revenues using equations 4 and 5. For each plant, we repeat the simulation 100 times and report averages over the simulations.
} 
allows us to understand the importance of market selection effects while isolating the role of the plant's history allows us to understand the importance of sunk costs in the decision process. We do this by calculating the marginal benefit to each activity. Table 8 reports the marginal benefits of exporting for a plant with different combinations of productivity (rows) and previous R\&D (columns). The second and third columns report values of $V_{t}^{E}\left(\omega_{t}, d_{t-1}\right)$, the future payoff to being an exporter, while columns four and five report $V_{t}^{D}\left(\omega_{t}, d_{t-1}\right)$, the future payoff to remaining in the domestic market. ${ }^{27}$ All the values are increasing in the productivity level, reflecting the increase in profits in both markets with higher productivity. For each value of $\left(\omega_{t}, d_{t-1}\right), V_{t}^{E}\left(\omega_{t}, d_{t-1}\right)>V_{t}^{D}\left(\omega_{t}, d_{t-1}\right)$ reflecting both the fact that current exporters do not have to pay the sunk cost of entering the export market in the next period and the impact of learning-by-exporting on future productivity.

Table 8 here

The sixth column reports the marginal benefit of exporting for a plant that conducted R\&D in $t-1$, defined in equation 15 as $M B E\left(\omega_{t} \mid d_{t-1}=1\right)$. It is positive, reflecting the fact that a plant that does both activities has a higher future productivity trajectory, and is increasing in current productivity implying that a high productivity producer is more likely to self select into the export market. The benefit of exporting for a plant that did not invest in $\mathrm{R} \& \mathrm{D}, M B E\left(\omega_{t} \mid d_{t-1}=\right.$ 0 ), is reported in the last column and it also is positive and increasing in the level of current productivity. Comparing the last two columns we see that $\triangle M B E\left(\omega_{t}\right)=M B E\left(\omega_{t} \mid d_{t-1}=\right.$ 1) $-M B E\left(\omega_{t} \mid d_{t-1}=0\right)$ is negative and the magnitudes are very small, implying that the prior R\&D experience has very little impact on the return to exporting. ${ }^{28}$ Heterogeneity in current productivity will be a major factor distinguishing which plants participate in the export market and its effect will swamp differences due to past R\&D experience.

The marginal benefits of exporting can be translated into probabilities of exporting by comparing them with the relevant cost faced by the plant: the sunk cost if the plant was not an exporter in the prior year $\left(e_{t-1}=0\right)$ and the fixed cost if it was $\left(e_{t-1}=1\right)$. The coefficients $\gamma^{F}$ and $\gamma^{S}$ in Table 5 are each the mean of an exponential random variable. The higher estimate for $\gamma^{S}$ indicates that the sunk cost distribution will have much more of the mass concentrated in high cost values, so, for the same marginal benefit, a plant will be more likely to remain in the export market than to enter the export market. The probabilities of exporting are reported in Table 9 for different combinations of productivity (the rows) and $d_{t-1}$ for both nonexporters and exporters (columns 2-5). First, the export probabilities are always increasing in current productivity. The difference between a low and high productivity plant is substantial and this shows the importance of selection based on current productivity. Second, the probabilities are largest for past exporters $\left(e_{t-1}=1\right)$. For example, a plant with productivity level 0.49 and prior R\&D investment, will have a .710 probability of remaining in the export market but only a .309 probability of entering. This is the effect of the sunk cost of entry and it can also be substantial for the intermediate range of plant productivity.

A comparison of Tables 8 and 9 provides insight on the fixed and sunk costs that the plants will incur to be exporters. As discussed in section I.C, the costs are the expenditures that a plant must make to participate in the export market and these differ across plants. Plants that have a

\footnotetext{
${ }^{27}$ These are averages across values of the capital stock and export demand shock and use the dynamic parameter estimates from Model 2 in Table 5

${ }^{28}$ The negative sign for $\triangle M B E\left(\omega_{t}\right)$ is due to the negative value for the $\alpha_{6}$ coefficient in Table 3 , which implies that the marginal contribution of exporting is larger for plants that did not have prior R\&D experience. If we set this coefficient equal to zero, $\triangle M B E\left(\omega_{t}\right)$ will take positive values, so that plants that conducted R\&D in the past will have a higher return to exporting. The magnitude of the effect, however, remains quite small. At the mean productivity level, $\triangle M B E\left(\omega_{t}=0.49\right)=4.3$ rather than the -1.6 seen from Table 8 . Our conclusion that prior R\&D experience has little impact on the return to exporting is not affected by this change.
} 
fixed or sunk cost less than the value of $M B E\left(\omega_{t} \mid d_{t-1}\right)$ will choose to export. Columns 2-5 of Table 9 show the proportion of plants that will have costs less than this threshold. For example, $M B E\left(\omega_{t}=0.49 \mid d_{t-1}=1\right)$ is 31.3 million NT dollars and 71.0 percent of the prior period exporting plants will have a fixed cost less than this value and 30.9 percent of the prior period nonexporters will have a sunk cost less than this value and thus choose to export in the current year. For each combination of the state variables $\left(\omega_{t}, d_{t-1}, e_{t-1}\right)$ the mean fixed/sunk cost of the plants that choose to export is the truncated mean of an exponential distribution with location parameter given in Table 5 and truncation point given by $M B E$. These means are reported in the 2nd and 3rd columns of Table 10 for different values of $\omega .{ }^{29}$ For example, for the productivity level $\omega_{t}=0.49$, the plants that choose to continue in the export market will have a mean fixed cost of 6.21 million NT dollars while the plants that choose to enter the export market will have a mean sunk cost of 12.32 million NT dollars. The sunk cost of entry is always larger than the fixed cost of maintaining an export market presence. The mean fixed and sunk cost of the exporters rises with the plant's productivity level since the return to exporting, $M B E$, rises with productivity. High productivity plants will find it profitable to make larger fixed or sunk cost outlays in order to export than their low productivity competitors.

Table 9 here

\section{Table 10 here}

Tables 11 and 12 conduct a similar analysis of the marginal benefit and probability of conducting R\&D. Columns 2-5 of Table 11 report the values of $E_{t} V_{t+1}\left(\omega_{t} \mid e_{i t}, d_{i t}\right)$ defined in equation 13. First, the future plant value is increasing in the level of productivity and the magnitudes vary substantially between low and high productivity plants. Second, for any value of $\omega, E V_{t+1}$ is greatest for plants that do both activities, followed by R\&D plants, exporting plants, and plants that do neither activity. This reflects the difference in the parameters of the productivity process reported in Table 3 as well as the impact of sunk costs. The last two columns report the marginal benefit of R\&D, $M B R\left(\omega_{t} \mid e_{t}\right)$ defined in equation 14. This increases substantially with the level of productivity implying that high productivity plants will be more likely to self select into R\&D investment. Comparing the last two columns reveals the impact of exporting on the return to R\&D. $\triangle M B R\left(\omega_{t}\right)=M B R\left(\omega_{t} \mid e_{t}=1\right)-M B R\left(\omega_{t} \mid e_{t}=0\right)$ is negative implying a higher return to $R \& D$ for nonexporting plants. This sign of this interaction effect follows from the negative coefficient on $\alpha_{6}$ but the magnitudes are quite small. ${ }^{30}$

Table 12 reports the probability of undertaking R\&D for different combinations of $\omega_{t}, e_{t}$, and $d_{t-1}$. The probabilities increase with productivity for all combinations of $e_{t}$ and $d_{t-1}$. Comparing columns 2 and 3 we observe that, for any level of productivity, the probability of R\&D is always higher when $d_{t-1}=1$. This reflect the fact that the sunk cost of starting the operation is more substantial than the fixed cost of maintaining it. The same pattern holds in columns 4 and 5 .

Table 11 here

Table 12 here

\footnotetext{
${ }^{29}$ We report the values for plants that conducted $\mathrm{R} \& \mathrm{D}$ in the prior year, $d_{t-1}=1$. The cost values for plants that did not conduct R\&D are approximately .1 to .4 million NT dollars higher, reflecting the slightly higher value of $M B E$ in Table 8 for these plants.

${ }^{30}$ If we set $\alpha_{6}=0, \triangle M B R\left(\omega_{t}=0.49\right)=11.3$ rather than -3.6 from Table 11. As seen above with $\triangle M B E$, the interaction effect of exporting on the return to $R \& D$ is small.
} 
The value of $M B R\left(\omega_{t} \mid e_{t}\right)$ in Table 11 provides the marginal benefit of conducting R\&D which is also the threshold expenditure necessary for a plant to undertake R\&D. Plants with sunk or fixed costs less than this threshold will choose to invest in R\&D. The mean value of the fixed and sunk cost of R\&D, for the set of plants that choose to invest, are reported in the last two columns of Table $10 .{ }^{31}$ For example, for plants with productivity level $\omega_{t}=0.49$ and $e_{t}=1$, the value of conducting R\&D is 34.3 million NT dollars, 32.9 percent of the plants that previously conducted $R \& D$ will have fixed costs less than this value, and the average realized $R \& D$ expenditure among this group is 12.8 million NT dollars. In addition, 7.5 percent of the plants that did not previously invest in $\mathrm{R} \& \mathrm{D}$ will choose to enter and the average sunk startup expenditure among this group is 15.64 million NT dollars. As we observed with exporting, the mean sunk startup costs for $R \& D$ are greater than the mean fixed cost of continuing an R\&D program. Comparing the two activities, the mean costs of $R \& D$ are greater than the mean costs of exporting at each productivity level, which contributes to the fact that R\&D investment rates are lower than export rates. For plants with productivity above 0.32 , this is reinforced by the fact that the marginal return to R\&D is less than the marginal return to exporting, $M B R<M B E$, so that high productivity plants are more likely to export than invest in $R \& D$. This is particularly true for high productivity plants that are entering the activity.

Overall, the results in Tables 8-12 allow us to draw four conclusions about the determinants of the plant's decision regarding exporting and R\&D investment. First, current productivity has a large positive impact on the return to both activities, particularly exporting. Self-selection based on the plant's productivity is a major reason a plant chooses to export or invest in R\&D. It is further reinforced by the dynamic impact this choice has on the plant's future productivity. Second, the costs of exporting are less than the comparable costs of conducting R\&D and this contributes to the fact that plants are more likely to export than invest in R\&D. Third, a history of prior investment in the activity, so that fixed costs rather than sunk costs are the relevant cost comparison, leads to substantially higher participation rates. Fourth, the indirect effect of each activity on the net returns to the other is small and has little impact on the probability the plant exports or conducts R\&D. It is important to emphasize that each of these effects is derived holding the export market size fixed and only summarizes how variation in the state variables, productivity and prior exporting or R\&D experience, affect the payoffs and probability of undertaking each investment activity. In the next section we use the estimated model to simulate how an exogenous increase in the size of the export market will impact long-run patterns of exporting, R\&D investment, and productivity.

\section{E. Export Market Size and Endogenous Productivity Evolution}

Trade liberalization results in an expansion of export market size or a reduction of variable trade costs which increases plant profits in the export market. In turn, this can affect the firm's incentives to invest in new technology or innovation activities, as modeled by Constantini and Melitz (2008) and Atkeson and Burstein (forthcoming). In this section we conduct a counterfactual exercise quantifying the impact of an exogenous increase in export market profits on the plant's decision to export and conduct R\&D and the impact this has on the productivity trajectory of the plant. In our structural model, an increase in export market size or a decrease in variable costs would act on the intercept of the export profit/revenue function, $\ln \Phi^{X}$ in equation 5. By changing this coefficient we can simulate the long-run impact on the plant's decisions and productivity. In addition we can compare how this market expansion will alter plant decisions when productivity is endogenous versus when productivity is exogenous to the plant. This allows us to isolate the mechanisms that work to alter plant investments in R\&D or new technology

\footnotetext{
${ }^{31}$ We report the mean cost values for the plants that choose to export. The mean realized costs for plants that do not export will be slightly higher because of the higher value of $M B R$ for these plants seen in Table 11. The differences in magnitude, however, are small and the patterns are identical to the ones we discuss in the text.
} 
in the face of trade liberalization, as measured by Bustos (forthcoming) and Lileeva and Trefler (forthcoming).

In this exercise we increase export market profits by increasing the value of $\ln \Phi^{X}$ by .37 . This is equivalent to a reduction in the average tariff faced by Taiwanese exporters from approximately 10 to 5 percent. To analyze the effect on plant decisions and productivity change we solve for the optimal R\&D and exporting choices for each plant using the new intercept for the export revenue function and simulate the plant's productivity trajectory for 15 years into the future. ${ }^{32}$ We repeat this simulation thirty times and then summarize the results by averaging the proportion of exporting plants, proportion of R\&D performers, and productivity across plants in each year. Table 13 reports the percentage change in each of these variables resulting from the increase in market size, for years $2,5,10$, and 15. The top panel of Table 13 provides results for an environment where productivity is endogenously affected by both the plant's discrete R\&D and export choice as modeled in equation 8. The remainder of the table examines the plant choices and productivity path under more restrictive conditions on the productivity process: exporting has no direct effect $\left(\alpha_{5}=\alpha_{6}=0\right)$, R\&D has no direct effect $\left(\alpha_{4}=\alpha_{6}=0\right)$, and productivity is exogenous to the plant $\left(\alpha_{4}=\alpha_{5}=\alpha_{6}=0\right) \quad$ By comparing the results under these different scenarios for the productivity process we can quantify the importance of the plant's endogenous choice of R\&D and exporting on future productivity when export markets expand.

\section{Table 13 here}

The top panel of Table 13 shows that market expansion raises the proportion of exporters and plants conducting R\&D immediately as a result of the increase in export market profits. The proportions continue to rise over time as the additional impact of the endogenous increase in productivity plays a role. After 15 years the proportion of exporting plants will be higher by 10.2 points and the proportion of R\&D performers by 4.7 points. Approximately half of each increase is observed in the first year and the remainder is due to further continual increases over time. Mean productivity shows a small increase in year 2 after the market expansion, 0.5 percent, but this increases steadily to 5.3 percent after 15 years. Overall, in an environment where productivity endogenously responds to the plant's export and R\&D decisions, the larger export market results in increases in participation in both activities and a resulting gain in productivity.

The expansion in the proportion of plants exporting and investing in R\&D is consistent with the reduced form evidence presented by Bustos (forthcoming). She reports that the average reduction in Brazil's tariffs of 24 percentage points increases the export proportion of Argentine firms by 10-14 points, depending on regression specification. She also reports that this average tariff reduction leads to a 7 point increase in her index of innovation (the proportion of times firms report "yes" to questions about their innovation activity or use of new technology). Lileeva and Trefler (forthcoming) focus on a group of Canadian firms induced to export to the U.S. market by a reduction in U.S. tariffs. Using a before-and-after comparison of labor productivity for this group, they find that productivity increases, but only for the firms with initially low-productivity. Although the mechanism is different, we also find a hetergenous response of R\&D investment to expansion of the market across plants with different productivity. The rise in the probability of conducting R\&D is determined by both the shift in the $M B R$ and the shape of the distribution of sunk or fixed costs of R\&D. In our case, the market expansion generates a larger increase in the probability of R\&D for lower and medium productivity plants, regardless of the plant's export status. Because of the endogeneity of productivity this R\&D investment will lead to higher future productivity for these plants.

In the remainder of Table 13 we simulate the effect of the market expansion when the plants face a more restrictive productivity process. A purely exogenous productivity process is sum-

\footnotetext{
${ }^{32}$ The initial distribution of the state variables, productivity, prior exporting, prior R\&D investment, and capital, is chosen to match the distribution observed in the data.
} 
marized in the bottom panel of the table. In this case, the market expansion increases $M B E$ and increases the proportion of plants that export, but there is no incentive to invest in R\&D and no effect on within-plant future productivity. The proportion of exporting plants rises by 5.5 points over the 15 year horizon, with the majority of the increase coming immediately and the remainder due to the effect of sunk entry costs creating hysteresis in the participation decision This is the effect modeled in Das, Roberts, and Tybout (2007). In contrast, in the environment with endogenous productivity, there is a larger expansion in the export proportion and an additional increase in the R\&D proportion after the second year. This results from the feedback effect of increased productivity on the incentive to export and conduct R\&D.

The second panel in Table 13 simulates the plant's decisions in an environment where there is no direct effect of export status on productivity (no learning-by-exporting). In this case the plant invests in R\&D because of its impact on future productivity and exports in response to the increase in export profits. Comparing this environment with the top panel, we observe a smaller increase in export proportion because the benefit of exporting comes only in the form of current and future profit, but not from increases in future productivity. There is also a smaller increase in the proportion of plants that conduct $R \& D$ because the improvement in productivity is not as substantial as in the top panel. The difference in the top two panels shows the additional contribution of learning-by-exporting to the productivity improvement when the market expands.

The third panel in Table 13 eliminates any role for R\&D. In this case there is no incentive to invest in R\&D but exporting will be valuable because it both increases profits and improves future productivity. In this case we observe an increase of mean productivity of 1.8 percent over 15 years, less than we observe in the environment where only R\&D matters. The productivity also increases slower because, as shown in our estimates of the productivity process in Table 3 , exporting has a smaller direct effect on future productivity than R\&D.

Overall, the comparison of the top panel with the more restrictive environments in the rest of the table shows the important role of endogenous productivity. The export market expansion initially leads to only a small increase in productivity, but it induces both more export market participation and more R\&D investment. The cumulative effect of these additional activities by the plants leads to a substantial increase in productivity over longer time periods. Mapping the productivity trajectory of these plants over time and comparing the paths under alternative productivity processes can only be done with a dynamic model that recognizes the endogeneity of the export and R\&D decision.

\section{Conclusions}

This paper estimates a dynamic structural model that captures both the behavioral and technological linkages between R\&D, exporting, and productivity. It characterizes a producer's joint dynamic decision process for exporting and R\&D investment as depending on their productivity, export demand, plant size, prior export and R\&D experience, and fixed and sunk costs of both activities. It also describes how a plant's R\&D and exporting endogenously affect their future productivity trajectories. We estimate the model using plant-level data for the Taiwan electronics industry from the period 2000-2004.

There are six broad conclusions we draw about the sources of productivity evolution among Taiwan's electronics producers. First, plant productivity evolves endogenously in response to the plant's choice to export or invest in R\&D. Relative to a plant that does neither activity, export market participation raises future productivity by 1.96 percent, R\&D investment raises it by 4.79 percent and undertaking both activities raises it by 5.56 percent. Second, the marginal benefits of both exporting and R\&D increase with the plant's productivity and high productivity plants have particularly large benefits from exporting. This leads to the self selection of high productivity plants into both activities. When combined with the fact that exporting and R\&D investment then lead to endogenous productivity improvements, this further reinforces the importance of self selection based on current productivity as the major factor driving the decision to export 
and invest in R\&D. Third, the sunk cost of beginning either activity is greater than the fixed cost of maintaining the activity. For a given productivity level, an existing exporter is much more likely to continue exporting than a nonexporter is to enter the market and the differences in the probability of exporting are often quite substantial between the two groups. The same is true of $R \& D$ investment. Fourth, the sunk and fixed costs of investing in R\&D are greater than the sunk and fixed costs of exporting which results in a larger proportion of plants choosing to export than to conduct R\&D. This occurs even though $R \& D$ has a larger direct effect on future productivity. Fifth, the results indicate that the interdependence of the two activities is not a very important factor in the plant's decisions. Investment in R\&D has relatively little impact on the return to exporting and there is very little difference in the return to R\&D between exporters and nonexporters. As a result, the fact that a plant exports, for example, has virtually no effect on its probability of investing in R\&D. Finally, our counterfactual exercises show that a reduction in trade costs will have a significant effect on the probabilities that a plant exports and invests in R\&D. These in turn lead to an increase in mean productivity that is twice as large as the increase that would occur under more restrictive environments. The combination of larger export markets and the plants ability to invest and endogenously affect its future productivity contributes to larger productivity gains.

Overall, the empirical findings emphasize the important role of underlying heterogeneity in productivity as the driving force determining which Taiwanese electronics plants choose to export and/or invest in R\&D. This is further reinforced by the fact that these activities result in future productivity improvements. The framework used here can be extended in several ways. If more detailed data were available on the uses of $R \& D$, particularly the distinction between R\&D used to improve the efficiency of the production process versus develop new products or improve product quality, it would be possible to distinguish the return to each type of investment. In particular, whether one of the investment tools had a more substantial impact on the return in the export market. In addition, while we have focused attention on heterogeneity in productivity in this paper, we also find, like Das, Roberts, and Tybout (2007) find using Colombian manufacturing data, that plant-specific export market shocks also play an important role in the export decision. If more detailed data were available on the characteristics of the products it could be possible to augment this framework with a richer demand structure that would allow us to treat export market heterogeneity as resulting from the plant's R\&D or product quality choices, rather than as an exogenous process. 


\section{REFERENCES}

Atkeson, Andrew and Ariel Burstein. Forthcoming. "Innovation, Firm Dynamics, and International Trade." Journal of Political Economy.

Aw, Bee Yan, Mark J. Roberts and Tor Winston. 2007. "Export Market Participation, Investments in R\&D and Worker Training, and the Evolution of Firm Productivity." The World Economy, 14(1): 83-104.

Aw, Bee Yan, Mark J. Roberts and Daniel Yi Xu. 2008. "R\&D Investments, Exporting, and the Evolution of Firm Productivity." American Economic Review, Papers and Proceedings, 98(2): 451-456.

Baldwin, John R and Wulong Gu. 2004. "Export Market Participation and Productivity Performance in Canadian Manufacturing." Canadian Journal of Economics, 36: 634-657.

Bernard, Andrew B. and J. Bradford Jensen. 1997. "Exporters, Skill Upgrading, and the Wage Gap." Journal of International Economics, 42(1):3-31.

Binswanger, Hans. 1974. "The Measurement of Technical Change Biases with Many Factors of Production." American Economic Review, 64(6): 964-976.

Branstetter, Lee and Jong-Rong Chen. 2006. "The Impact of Technology Transfer and R\&D on Productivity Growth in Taiwanese Industry: Microeconometric Analysis Using Plant and Firm-Level Data." Journal of the Japanese and International Economies, 20: 177-192.

Bustos, Paula. Forthcoming. "Multilateral Trade Liberalization, Exports and Technology Upgrading: Evidence on the Impact of MERCOSUR on Argentinean Firms." American Economic Review.

Clerides, Sofronis K., Saul Lach, and James R. Tybout.1998. "Is Learning By Exporting Important? Micro-Dynamic Evidence from Colombia, Mexico, and Morocco." Quarterly Journal of Economics, 113(3): 903-947.

Cohen, Wesley M. and Daniel A. Levinthal. 1989. "Innovation and Learning: The Two Faces of R\&D." Economic Journal, 99: 569-596.

Constantini, James A., and Marc J. Melitz. 2008. "The Dynamics of Firm-Level Adjustment to Trade Liberalization." in The Organization of Firms in a Global Economy, ed. E. Helpman, D. Marin, and T. Verdier. Cambridge: Harvard University Press.

Criscuolo, Chiara, Jonathan Haskel, and Mathew Slaughter. 2005. "Global Engagement and the Innovation Activities of Firms." NBER Working Paper 11479.

Damijan, Jože P., Črt Kostevc, and Sašo Polanec. 2008. "From Innovation to Exporting or Vice Versa?" LICOS Discussion Paper 204.

Das, Sanghamitra, Mark J. Roberts and James R. Tybout. 2007. "Market Entry Costs, Producer Heterogeneity, and Export Dynamics." Econometrica, 75(3): 837-873.

Doraszelski, Ulrich and Jordi Jaumandreu. 2007. "R\&D and Productivity: Estimating Production Functions When Productivity is Endogenous." Working Paper, Department of Economics, Harvard University.

Greenaway, David and Richard Kneller. 2007. "Firm Heterogeneity, Exporting and Foreign Direct Investment." Economic Journal, 117: F134-F161.

Griliches, Zvi. 1979. "Issues in Assessing the Contribution of Research and Development to Productivity Growth." The Bell Journal of Economics, 10(1): 92-116.

Griliches, Zvi. 1998. R\&D and Productivity: The Econometric Evidence. Chicago: The University of Chicago Press.

Hallward-Driemeier, Mary, Giuseppe Iarossi, and Kenneth L. Sokoloff. 2002. "Exports and Manufacturing Productivity in East Asia: A Comparative Analysis with Firm-Level Data." NBER Working Paper 8894. 
Heckman, James J. 1981. "The Incidental Parameters Problem and the Problem of Initial Conditions in Estimating a Discrete Time-Discrete Data Stochastic Process and Some Monte Carlo Evidence." in Structural Analysis of Discrete Data with Econometric Applications, ed. Charles Manski and Daniel McFadden, 179-195. Cambridge, MA: MIT Press.

Hobday, Michael. 1995. Innovation in East Asia: The Challenge to Japan, Brookfield, VT: Edward Elgar Publisher.

Iacovone, Leonardo and Beata S. Javorcik. 2007. "Getting Ready: Preparation for Exporting." Working Paper.

Jorgenson, Dale, Frank Gollop, and Barbara Fraumeni. 1987. Productivity and U.S. Economic Growth. Cambridge, MA: Harvard University Press.

Levy, Brian. 1994. "Technical and Marketing Support Systems for Successful Small and Medium Sized Enterprises in Four Countries." Policy Research Working Paper, No. 1400, World Bank.

Lileeva, Alla and Daniel Trefler. Forthcoming. "Improved Access to Foreign Markets Raises Plant-Level Productivity... for Some Plants." Quarterly Journal of Economics.

Melitz, Marc J. 2003. "The Impact of Trade on Aggregate Industry Productivity and IntraIndustry Reallocations." Econometrica, 71(6): 1695-1725.

Olley, G. Steven and Ariel Pakes. 1996. "The Dynamics of Productivity in the Telecommunications Equipment Industry." Econometrica, 64(6): 1263-1297.

Pack, Howard. 1992. "New Perspectives on Industrial Growth in Taiwan." in Taiwan from Developing to Mature Economy, ed. G. Ranis. Boulder. CO: Westview Press.

Roberts, Mark J. and James R. Tybout. 1997. "The Decision to Export in Colombia: An Empirical Model of Entry with Sunk Costs." American Economic Review, 87(4): 545-564.

Rust, John. 1997. "Using Randomization to Break the Curse of Dimensionality." Econometrica, 65(3): 487-516.

Stevenson, Rodney. 1980. "Measuring Technological Bias." American Economic Review, 70(1): 162-173.

Sun, Chia-Hung. 2005. The Growth Process in East Asian Manufacturing Industries. Edward Elger Publisher.

Westpahl, Larry E. 2002. "Technology Strategies for Economic Development in a Fast Changing Global Economy." Economics of Innovation and New Technology, 11: 275-320.

Xu, Daniel Yi. 2008. "A Structural Model of R\&D, Firm Heterogeneity, and Industry Evolution." Working Paper, Department of Economics, New York University. 
Table 1 - Domestic and Export Sales (millions of NT\$)

\begin{tabular}{cccc}
\hline \hline & & \multicolumn{2}{c}{ Exporters } \\
& $\begin{array}{c}\text { Nonexporters } \\
\text { Median Domestic Sales }\end{array}$ & Median Domestic Sales & Median Export Sales \\
\cline { 2 - 4 } 2002 & 22.2 & 52.8 & 33.6 \\
2003 & 17.0 & 36.4 & 32.5 \\
2004 & 17.3 & 42.7 & 30.9 \\
& 17.8 & 38.6 & 30.7 \\
\cline { 2 - 4 } 2000 & Average Domestic Sales & Average Domestic Sales & Average Export Sales \\
\cline { 2 - 4 } 2002 & 69.5 & 390.0 & 586.0 \\
2003 & 55.8 & 363.1 & 490.5 \\
2004 & 57.2 & 385.9 & 576.3 \\
\hline
\end{tabular}

Table 2 - Annual Transition Rates for Continuing Plants

\begin{tabular}{ccccc}
\hline \hline \multirow{2}{*}{ Status year t } & \multicolumn{4}{c}{ Status Year $\mathrm{t}+1$} \\
\hline & Neither & only R\&D & only Export & Both \\
All Firms & 0.563 & 0.036 & 0.255 & 0.146 \\
Neither & 0.871 & 0.014 & .0 .110 & 0.005 \\
only R\&D & 0.372 & 0.336 & 0.058 & 0.233 \\
only Export & 0.213 & 0.010 & 0.708 & 0.070 \\
Both & 0.024 & 0.062 & 0.147 & 0.767 \\
\hline
\end{tabular}


Table 3 - Demand, Cost and Productivity Evolution Parameter Estimates (standard errors)

\begin{tabular}{|c|c|c|}
\hline Parameter & Discrete R\&D & Continuous R\&D \\
\hline $1+1 / \eta_{D}$ & $0.8432(0.0195)^{*}$ & $0.8432(0.0195)^{*}$ \\
\hline $1+1 / \eta_{X}$ & $0.8361(0.0164)^{*}$ & $0.8361(0.0164)^{*}$ \\
\hline$\beta_{k}$ & $-0.0633(0.0052)^{*}$ & $-0.0636(0.0051)^{*}$ \\
\hline$\alpha_{0}$ & $0.0879(0.0198)^{*}$ & $0.0866(0.0194)^{*}$ \\
\hline$\alpha_{1}$ & $0.5925(0.0519)^{*}$ & $0.5982(0.0511)^{*}$ \\
\hline$\alpha_{2}$ & $0.3791(0.0915)^{*}$ & $0.3777(0.0912)^{*}$ \\
\hline$\alpha_{3}$ & $-0.1439(0.0585)^{*}$ & $-0.1592(0.0588)^{*}$ \\
\hline$\alpha_{4}$ & $0.0479(0.0099)^{*}$ & $0.0067(0.0012)^{*}$ \\
\hline$\alpha_{5}$ & $0.0196(0.0046)^{*}$ & $0.0197(0.0045)^{*}$ \\
\hline$\alpha_{6}$ & $-0.0118(0.0115)$ & $-0.0022(0.0014)$ \\
\hline$S E\left(\xi_{i t}\right)$ & 0.1100 & 0.1098 \\
\hline sample size & 3703 & 3703 \\
\hline
\end{tabular}

Table 4 - Reduced Form Participation and Export Revenue Equations

\begin{tabular}{cccccc}
\hline \hline & & & \\
Dependent Variable & Coeff on $\omega_{i t}$ & Coeff on $k_{i t}$ & Coeff on $e_{i t-1}$ & Coeff on $d_{i t-1}$ & Other \\
\hline \multicolumn{5}{c}{ Bivariate Probit on Exporting and R\&D } \\
Exporting $e_{i t}$ & $1.63(\mathrm{t}=10.3)$ & $0.064(\mathrm{t}=3.38)$ & $1.80(\mathrm{t}=32.1)$ & $0.186(\mathrm{t}=2.26)$ & $\rho=0.168$ \\
R\&D $d_{i t}$ & $1.65(\mathrm{t}=7.12)$ & $0.205(\mathrm{t}=7.52)$ & $0.344(\mathrm{t}=4.38)$ & $1.86(\mathrm{t}=23.3)$ & $\rho$ \\
\hline \multicolumn{5}{c}{ Export Revenue } \\
$\ln r_{i t}^{X}$ & $6.45(\mathrm{t}=36.1)$ & $0.409(\mathrm{t}=20.3)$ & $\operatorname{Var}(z)=0.72$ \\
\hline \multicolumn{7}{c}{ Export Revenue with Fixed Effect $\left(z_{i}\right)$} \\
\hline
\end{tabular}


Table 5 - Dynamic Parameter Estimates

\begin{tabular}{cccccc}
\hline \hline \multicolumn{3}{c}{ Means and Standard Deviations of the Posterior Distribution } \\
\hline \multicolumn{4}{c}{ Model 1 } & \multicolumn{4}{c}{ Model 2 } \\
\hline Parameter & Mean & St. Dev. & Parameter & Mean & St. Dev. \\
\hline$\gamma^{I}$ (R\&D FC) & 67.606 & 3.930 & $\gamma_{1}^{I}$ (size 1) & 46.265 & 7.038 \\
& & & $\gamma_{2}^{I}$ (size 2) & 66.596 & 3.423 \\
$\gamma^{D}$ (R\&D SC) & 354.277 & 31.377 & $\gamma_{1}^{D}$ (size 1) & 381.908 & 66.521 \\
& & & $\gamma_{2}^{D}$ (size 2) & 388.715 & 41.959 \\
$\gamma^{F}$ (Export FC) & 11.074 & 0.389 & $\gamma_{1}^{F}$ (size 1) & 5.733 & 0.295 \\
& & & $\gamma_{2}^{F}$ (size 2) & 15.962 & 0.704 \\
$\gamma^{S}$ (Export SC) & 50.753 & 3.483 & $\gamma_{1}^{S}($ size 1) & 51.852 & 6.046 \\
& & & $\gamma_{2}^{S}$ (size 2) & 67.401 & 6.676 \\
$\Phi_{X}$ (Export Rev Intercept) & 3.813 & 0.063 & $\Phi_{X}$ & 3.873 & 0.063 \\
$\rho_{Z}$ (Export Rev AR process) & 0.773 & 0.014 & $\rho_{Z}$ & 0.763 & 0.015 \\
$\log \sigma_{\mu}$ (Export Rev Std Dev) & -0.287 & 0.018 & $\log \sigma_{\mu}$ & -0.289 & 0.021 \\
\hline & & & & &
\end{tabular}

Table 6 - R\&D Investment Rates, Export Rates, and Productivity

\begin{tabular}{cccc}
\hline \hline & Year 2002 & Year 2003 & Year 2004 \\
\hline Export Market Participation Rate \\
Actual Data & 0.395 & 0.392 & 0.390 \\
Predicted & 0.370 & 0.371 & 0.371 \\
\hline \multicolumn{4}{c}{ R\&D Investment Rate } \\
Actual Data & 0.177 & 0.170 \\
Predicted & 0.172 & 0.168 & 0.169 \\
\hline \multicolumn{5}{c}{ Average Productivity } \\
Actual Data & 0.436 & 0.444 \\
Predicted & 0.449 & 0.441 & 0.167 \\
\hline
\end{tabular}


Table 7 - Predicted Transition Rates for Continuing Plants - Model 2

\begin{tabular}{cccccc}
\hline \hline \multirow{2}{*}{ Status year t } & & \multicolumn{4}{c}{ Status Year t+1 } \\
\hline \multirow{2}{*}{ Neither } & Predicted & 0.866 & 0.019 & 0.110 & 0.008 \\
& Actual & 0.871 & 0.014 & 0.110 & 0.005 \\
\hline only R\&D & Predicted & 0.476 & 0.214 & 0.116 & 0.193 \\
& Actual & 0.372 & 0.336 & 0.058 & 0.233 \\
\hline only Export & Predicted & 0.292 & 0.010 & 0.622 & 0.077 \\
& Actual & 0.213 & 0.010 & 0.708 & 0.070 \\
\hline Both & Predicted & 0.049 & 0.028 & 0.138 & 0.784 \\
& Actual & 0.024 & 0.062 & 0.147 & 0.767 \\
\hline
\end{tabular}

Table 8 - Marginal Benefit of Exporting (millions of NT dollars)

\begin{tabular}{ccccccc}
\hline \hline \multicolumn{2}{c}{$V_{t}^{E}$} & \multicolumn{2}{c}{$V_{t}^{D}$} & \multicolumn{2}{c}{$M B E=\pi_{t}^{X}+V_{t}^{E}-V_{t}^{D}$} \\
\hline$\omega_{t}$ & $d_{t-1}=1$ & $d_{t-1}=0$ & $d_{t-1}=1$ & $d_{t-1}=0$ & $d_{t-1}=1$ & $d_{t-1}=0$ \\
\hline-0.19 & 132.5 & 132.4 & 130.9 & 130.7 & 2.08 & 2.11 \\
\hline-0.02 & 138.9 & 138.5 & 136.3 & 135.9 & 3.69 & 3.76 \\
\hline 0.15 & 151.8 & 150.9 & 147.3 & 146.3 & 7.06 & 7.21 \\
\hline 0.32 & 179.4 & 176.3 & 170.9 & 167.4 & 14.7 & 15.2 \\
\hline 0.49 & 245.3 & 235.6 & 228.9 & 217.7 & 31.3 & 32.9 \\
\hline 0.67 & 392.6 & 365.3 & 362.9 & 331.9 & 65.3 & 69.1 \\
\hline 0.84 & 714.0 & 655.9 & 667.0 & 599.1 & 132.3 & 142.1 \\
\hline 1.01 & 1206.3 & 1117.4 & 1143.7 & 1041.5 & 266.8 & 280.1 \\
\hline 1.18 & 1911.3 & 1790.0 & 1834.0 & 1695.3 & 565.7 & 583.2 \\
\hline 1.35 & 2689.1 & 2568.8 & 2610.8 & 2471.7 & 1246.9 & 1265.7 \\
\hline
\end{tabular}


Table 9 - Export Policy Functions: $\operatorname{Pr}\left(e_{t}=1 \mid e_{t-1}, d_{t-1}\right)$

\begin{tabular}{ccccc}
\hline \hline & & & & \\
$\omega_{t}$ & $e_{t-1}=1$ & $e_{t-1}=0$ & $e_{t-1}=1$ & $e_{t-1}=0$ \\
& $d_{t-1}=1$ & $d_{t-1}=1$ & $d_{t-1}=0$ & $d_{t-1}=0$ \\
-0.19 & 0.156 & 0.032 & 0.157 & 0.032 \\
\hline-0.02 & 0.246 & 0.055 & 0.248 & 0.056 \\
\hline 0.15 & 0.365 & 0.098 & 0.369 & 0.099 \\
\hline 0.32 & 0.518 & 0.178 & 0.523 & 0.181 \\
\hline 0.49 & 0.710 & 0.309 & 0.718 & 0.317 \\
\hline 0.67 & 0.895 & 0.485 & 0.907 & 0.503 \\
\hline 0.84 & 0.969 & 0.653 & 0.980 & 0.693 \\
\hline 1.01 & 0.988 & 0.749 & 0.994 & 0.785 \\
\hline 1.18 & 0.997 & 0.835 & 0.999 & 0.873 \\
\hline 1.35 & 0.997 & 0.874 & 0.999 & 0.901 \\
\hline
\end{tabular}

Table 10 - Costs of Exporting and R\&D (millions of NT dollars)

\begin{tabular}{|c|c|c|c|c|}
\hline & \multicolumn{2}{|c|}{ Mean Export Costs among Exporters ${ }^{a}$} & \multicolumn{2}{|c|}{ Mean R\&D Costs among Investors } \\
\hline$\omega_{t}$ & Fixed Cost & Sunk Cost & Fixed Cost & Sunk Cost \\
\hline-0.19 & 0.97 & 1.036 & 1.32 & 1.34 \\
\hline-0.02 & 1.61 & 1.80 & 2.06 & 2.12 \\
\hline 0.15 & 2.64 & 3.33 & 3.41 & 3.59 \\
\hline 0.32 & 4.18 & 6.50 & 6.55 & 7.28 \\
\hline 0.49 & 6.21 & 12.32 & 12.83 & 15.64 \\
\hline 0.67 & 8.50 & 21.06 & 24.01 & 33.74 \\
\hline 0.84 & 9.86 & 30.72 & 36.28 & 60.78 \\
\hline 1.01 & 10.35 & 37.17 & 43.49 & 86.61 \\
\hline 1.18 & 10.67 & 43.54 & 49.35 & 113.93 \\
\hline 1.35 & 10.70 & 47.02 & 48.26 & 114.87 \\
\hline
\end{tabular}

a. For plants with $d_{t-1}=1$

b. For plants with $e_{t}=1$ 
Table 11 - Marginal Benefit of R\&D Investment (millions of NT dollars)

\begin{tabular}{ccccccc}
\hline \hline \multicolumn{2}{c}{$E V_{t+1}\left(d_{t}=1, e_{t}\right)$} & \multicolumn{2}{c}{$E V_{t+1}\left(d_{t}=0, e_{t}\right)$} & \multicolumn{2}{c}{$M B R$} \\
\hline$\omega_{t}$ & $e_{t}=1$ & $e_{t}=0$ & $e_{t}=1$ & $e_{t}=0$ & $e_{t}=1$ & $e_{t}=0$ \\
\hline-0.19 & 142.2 & 140.7 & 139.3 & 137.6 & 2.8 & 3.2 \\
\hline-0.02 & 150.2 & 147.9 & 145.8 & 142.9 & 4.5 & 5.0 \\
\hline 0.15 & 166.2 & 162.1 & 158.6 & 153.7 & 7.6 & 8.4 \\
\hline 0.32 & 200.3 & 192.1 & 184.6 & 175.1 & 15.7 & 17.0 \\
\hline 0.49 & 278.6 & 262.5 & 244.3 & 224.6 & 34.3 & 37.9 \\
\hline 0.67 & 447.3 & 417.5 & 371.2 & 333.0 & 76.1 & 84.5 \\
\hline 0.84 & 797.2 & 749.5 & 654.2 & 583.3 & 143.0 & 166.3 \\
\hline 1.01 & 1320.2 & 1255.6 & 1105.7 & 1004.1 & 214.5 & 251.5 \\
\hline 1.18 & 2065.7 & 1985.2 & 1773.5 & 1637.5 & 292.2 & 347.7 \\
\hline 1.35 & 2883.8 & 2802.5 & 2575.2 & 2425.5 & 308.6 & 377.0 \\
\hline
\end{tabular}

Table 12 - R\&D Policy Functions: $\operatorname{Pr}\left(d_{t}=1 \mid e_{t}, d_{t-1}\right)$

\begin{tabular}{ccccc}
$\omega_{t}$ & $e_{t}=1$ & $e_{t}=1$ & $e_{t}=0$ & $e_{t}=0$ \\
\hline & $d_{t-1}=1$ & $d_{t-1}=0$ & $d_{t-1}=1$ & $d_{t-1}=0$ \\
\hline-0.19 & 0.041 & 0.007 & 0.046 & 0.008 \\
\hline-0.02 & 0.063 & 0.011 & 0.070 & 0.012 \\
\hline 0.15 & 0.101 & 0.018 & 0.109 & 0.020 \\
\hline 0.32 & 0.182 & 0.036 & 0.192 & 0.039 \\
\hline 0.49 & 0.329 & 0.075 & 0.347 & 0.082 \\
\hline 0.67 & 0.566 & 0.155 & 0.590 & 0.169 \\
\hline 0.84 & 0.777 & 0.265 & 0.812 & 0.296 \\
\hline 1.01 & 0.872 & 0.360 & 0.899 & 0.399 \\
\hline 1.18 & 0.940 & 0.455 & 0.959 & 0.504 \\
\hline 1.35 & 0.928 & 0.451 & 0.951 & 0.505 \\
\hline
\end{tabular}


Table 13 - Plant Response to Exogenous Increase in Export Market Size

\begin{tabular}{|c|c|c|c|c|}
\hline Year & 2 & 5 & 10 & 15 \\
\hline \multicolumn{5}{|c|}{ Endogenous productivity: $\omega_{i t}=g\left(\omega_{i t-1}, d_{i t-1}, e_{i t-1}\right)+\xi_{i t}$} \\
\hline Change in Proportion of Exporters & 5.2 & 9.0 & 10.0 & 10.2 \\
\hline Change in Proportion of R\&D Performers & 2.5 & 3.5 & 4.1 & 4.7 \\
\hline Percentage Change in Mean Productivity & 0.5 & 1.5 & 3.7 & 5.3 \\
\hline \multicolumn{5}{|c|}{ Endogenous productivity: $\omega_{i t}=g\left(\omega_{i t-1}, d_{i t-1}\right)+\xi_{i t}$} \\
\hline Change in Proportion of Exporters & 2.0 & 3.9 & 4.0 & 4.4 \\
\hline Change in Proportion of R\&D Performers & 1.8 & 2.6 & 3.5 & 4.0 \\
\hline Percentage Change in Mean Productivity & 0.0 & 0.8 & 1.9 & 2.9 \\
\hline \multicolumn{5}{|c|}{ Endogenous productivity: $\omega_{i t}=g\left(\omega_{i t-1}, e_{i t-1}\right)+\xi_{i t}$} \\
\hline Change in Proportion of Exporters & 3.4 & 5.9 & 7.2 & 7.6 \\
\hline Percentage Change in Mean Productivity & 0.0 & 0.0 & 1.2 & 1.8 \\
\hline \multicolumn{5}{|c|}{ Exogenous productivity $\omega_{i t}=g\left(\omega_{i t-1}\right)+\xi_{i t}$} \\
\hline Change in Proportion of Exporters & 4.6 & 5.7 & 5.8 & 5.5 \\
\hline
\end{tabular}

